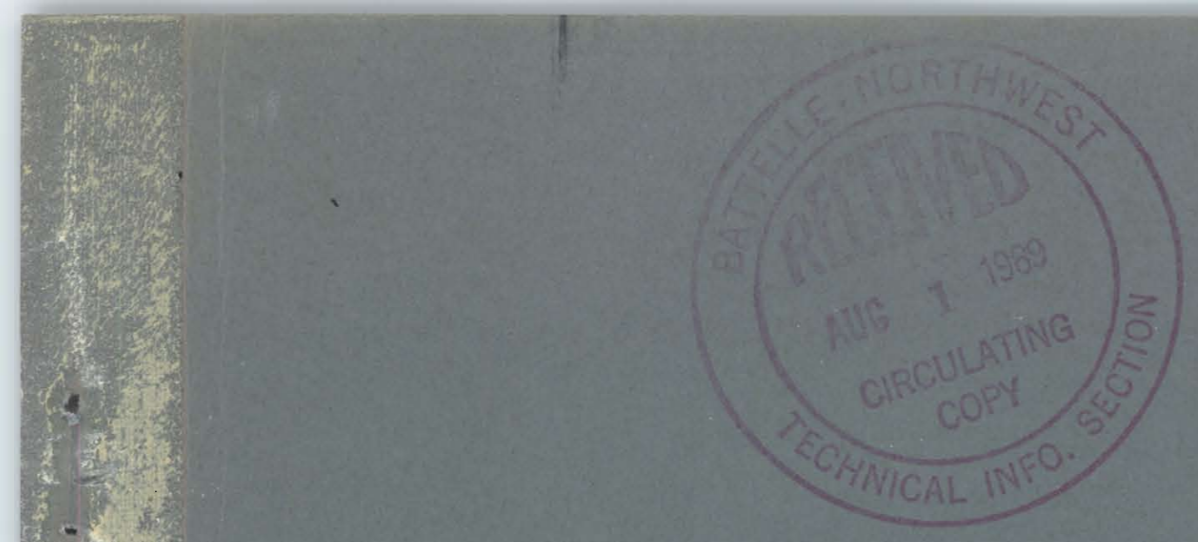

BNWL-1119

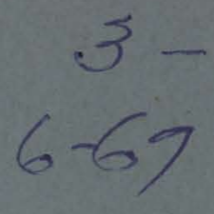

\title{
A REVIEW
}

\section{OF HEAVY WATER REACTOR PHYSICS}

June 1969

\section{AEC RESEARCH \& DEVELOPMENT REPORT}

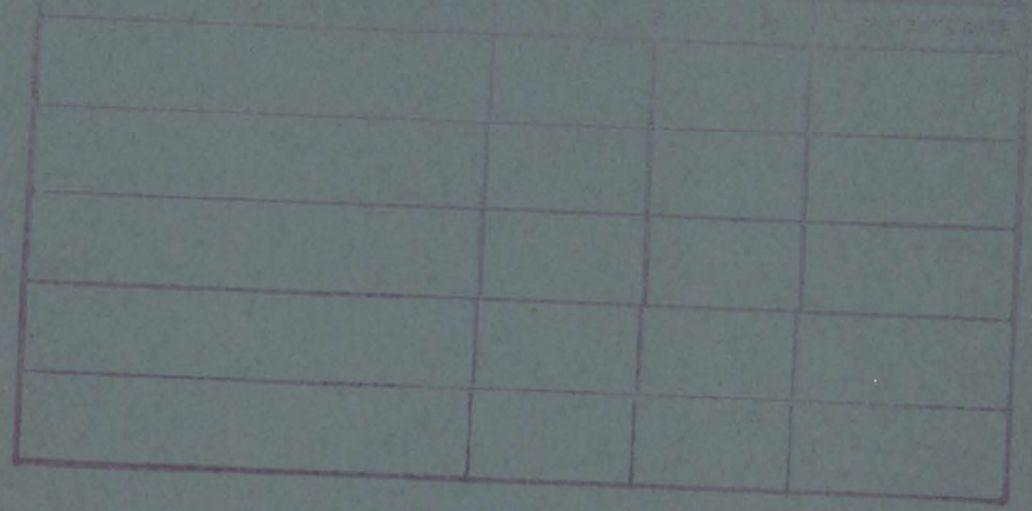




\section{LEGAL NOTICE}

This report was prepared as an account of Government sponsored work. Neither the Unifed States, nor the Commission, nor any person acting on behalf of the Commission:

A. Makes any warranty or representation, expressed or implied, with respect to the accuracy, completeness, or usefulness of the information contained in this report, or that the use of any information, apparatus, method, or process disclosed in this report may not infringe privately owned rights; or

B. Assumes any liabilities with respect to the use of, or for damages resulting from the use of any information, apparatus, method, or process disclosed in this report.

As used in the above, "person acting on behalf of the Commission" includes any employee or contractor of the Commission, or employee of such contractor, to the extent that such employee or contractor of the Commission, or employee of such contractor prepares, disseminates, or provides access to, any information pursuant to his employment or contract with the Commission, or his employment with such contractor.

\section{PACIFIC NORTHWEST LABORATORY \\ RICHLAND, WASHINGTON \\ operated by}

BATTELLE MEMORIAL INSTITUTE

for the

UNITED STATES ATOMIC ENERGY COMMISSION UNDER CONTRACT AT(45-1)-1830 
BNWL-1119

UC-80

Reactor Technology Special Distribution

A REVIEW OF HEAVY WATER REACTOR PHYSICS

by

V. O. Uotinen and L. C. Schmid

ERRATA

Page 23 should be numbered 22

Page 22 should be numbered 23

Reactor Physics Department

Physics and Engineering Division

May 1968

BATTELLE MEMORIAL INSTITUTE

PACIFIC NORTHWEST LABORATORY

RICHLAND, WASHINGTON 99352 
Printed in the United States of America Available from

Clearinghouse for Federal Scientific and Technical Information National Bureau of Standards, U.S. Department of Commerce Springfield, Virginia 22151

Price: Printed Copy $\$ 3.00$; Microfiche $\$ 0.65$ 
TABLE OF CONTENTS

Page No.

PREFACE - - -

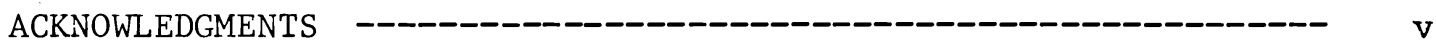

I. INTRODUCTION --- 1

II. CALCULATIONAL METHODS DEVELOPMENT - 3

A. HISTORICAL BACKGROUND -- 3

B. CELL CALCULATIONS DEVELOPMENT --- 5

1. U.S. METHODS --_-_-_-_- 5

2. FOREIGN METHODS --_-_-_-_-_-_-_-_-_-_-_--- 7

C. BASIC DATA AND METHODS USED IN CELL CALCULATIONS ---------- 9

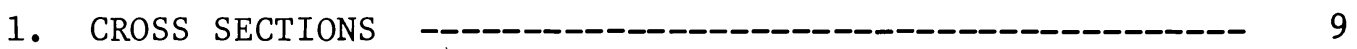

2. SLOWING DOWN TREATMENT IN HEAVY WATER REACTORS -.---_ 12

3. THE EXPERIMENTAL SCATTERING LAW FOR HEAVY WATER --_-_-_-_-_-_-_- 14

4. SCATTERING KERNELS FOR HEAVY WATER ------------ 22

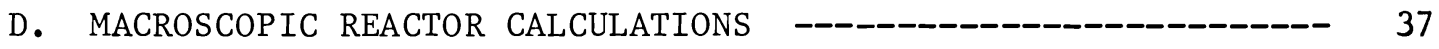

1. HOMOGENEOUS METHODS --- 37

2. HETEROGENEOUS METHODS --_- 38

III. REACTOR DATA AND ANALYTICAL CORRELATIONS ----_--_--_--_ 41

A. UNIFORM LATTICES OF RODS -_-_-_-_-_-_-_ 41

1. STATUS OF EXPERIMENTAL STUDIES --_-_-_-_-_-_-_ 41

2. STATUS OF ANALYTICAL CORRELATIONS --_-_-_-_-_-_--- 43

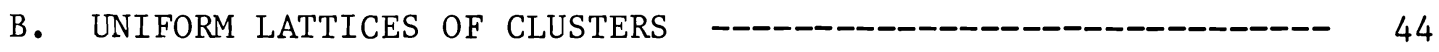

1. STATUS OF EXPERIMENTAL STUDIES - 44

2. STATUS OF ANALYTICAL CORRELATIONS --_-_-_-_--_---- 48

C. POWER REACTORS --_-_-_-_ 54

1. STATUS OF EXPERIMENTAL WORK --_-_-_-_-_-_ 54

2. STATUS OF ANALYTICAL CORRELATIONS --_-_-_-_-_-_-_-_ 59

IV. SUMMARY AND CONCLUSIONS --_-_-_-_-_-_-_-_-_-_-_-_-_ 63

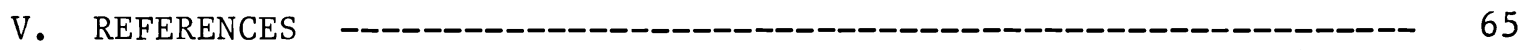




\section{PREFACE}

This report was prepared for the USAEC Heavy Water Reactor Program Office. The purpose of the report is to review the status of heavy water reactor physics studies, and to indicate areas where further studies are required. The contents of this report support the conclusions and recommendations made in the Heavy Water Program Plan, BNWL-656 Draft, March 1, 1968. 


\title{
ACKNOWLEDGMENTS
}

\author{
We appreciate the detailed reviews contributed by Alan G. Gibbs \\ on Scattering Kernels for Heavy Water and by $0 . K$. Harling on the \\ Experimental Scattering Law for Heavy Water. We acknowledge also \\ contributions by J. L. Carter, Jr. on Slowing Down Theory and by \\ B. R. Leonard, Jr, and R. C.Liikala on the Status of Cross Sections. \\ Finally, incorporated in this review are several comments and \\ suggestions that were made by J. L. Crandall and H. C. Honeck of \\ Savannah River Laboratory through correspondence with personnel of \\ the Heavy Water Reactor Program Office.
}




\section{A REVIEW OF HEAVY WATER REACTOR PHYSICS}

V. O. Uotinen and L. C. Schmid

\section{INTRODUCTION}

Many laboratories in the USA and abroad are actively engaged in heavy water reactor physics studies. The extent of these studies is evidenced by the large number of papers on $\mathrm{D}_{2} \mathrm{O}$ reactor physics presented in recent years at international conferences and symposia. World-wide interest in heavy water reactors is also evidenced by the increasing number of heavy water reactors being built around the world each year. Furthermore, it is likely that in the near future in many parts of the world the use of heavy water reactors will increase, mainly because of the advantages of being able to use natural uranium fuel.

The pressure tube concept has been extensively developed in Canada and studied by France, Sweden, Germany, India, Savannah River Laboratory, and Westinghouse. This reactor is well developed, inherently stable and has good neutron economy. The 20 MWe NPD and 200 MWe Douglas Point Candu reactors are operating in Canada now. The 500 MWe Pickering reactors are being considered for the future. Other examples are the 50 MWe MZFR reactor in Germany and the planned 200 MWe RAPP reactors in India.

The boiling $\mathrm{H}_{2} \mathrm{O}$ concept has been studied mainly in Canada, England, and Italy. It has a lowered $\mathrm{D}_{2} \mathrm{O}$ inventory and efficient heat removal. It suffers from poor neutron economy because of the $\mathrm{H}_{2} \mathrm{O}$ and one of the main physics problems is in the area of stability and control. The British 90 MWe SGHWR reactor is operating and studies are being conducted for a Canadian 250 MWe BLW reactor and an Italian 34 MWe CIRENE prototype. 
The pressure vessel concept with boiling $\mathrm{D}_{2} \mathrm{O}$ has excellent neutron economy and also requires careful investigation of the stability and control problems. This concept has been studied mainly in Sweden, Norway, and India. The Swedish 200 MWe Marviken reactor has begun operation and the Norwegian Halden HBWR has been in operation for several years. In addition to data from research programs in support of specific concepts, there are data available from general $\mathrm{D}_{2} \mathrm{O}$ programs of many other countries and of laboratories in the United States for evaluation of methods for $\mathrm{D}_{2} \mathrm{O}$ reactors in general.

Reactor physics can be categorized into two general areas. The first general area, kinetics, involves time-dependent phenomena. This includes the overall kinetics and control evaluations, and through them the physics aspects of the reactor safety analysis. A recent review of the status of kinetics studies for heavy water reactors has been published. (1)

The second general area, statics, involves time independent phenomena. Studies in this area determine the local neutron flux and fission power distributions, the neutron economy associated with different reactor materials, and the burnup properties of the fuel and controls. Also included in this area are the full reactor evaluations to determine the interactions between the various lattice components, the overall reactor flux and power distributions, the control system effects, and the overall reactor behavior. In addition, there are the determinations of the operating coefficient of reactivity, including temperature, density, and accident effects.

The purpose of this report is to review the status of heavy water reactor physics studies which fall into the broad category of statics. 
Several excellent reviews of heavy-water reactor physics have been presented in the past. Particular attention should be given to the IAEA Panel on Heavy Water Lattices (Vienna 1963), (2) the Geneva Conference of 1964 (including a paper describing lattice studies and critical experiments in the U.S.) ${ }^{(3)}$ and a review article on the Physics of Heavy Water Lattices by Honeck and Crandal1, (4) published in 1964.

In this report these earlier reports are taken as the starting point, and some major recent developments are reviewed in order to arrive at a reasonable picture of the current status of the technology of $\mathrm{D}_{2} \mathrm{O}$ reactor. physics. On the basis of this review some areas are indicated where further work seems necessary.

The development of calculational methods in both the United States and abroad will be discussed. Then some specific experimental and analytical studies will be discussed to indicate the current state of the art of $\mathrm{D}_{2} \mathrm{O}$ reactor physics.

II. CALCULATIONAL METHODS DEVELOPMENT

A. Historical Background

The traditional approach used in the analytical prediction of the physics behavior of $\mathrm{D}_{2} \mathrm{O}$ reactors is referred to as the recipe approach. As the word recipe implies, methods falling into this category are meant to be relatively simple and rapid. The foundation for these recipes is the classical description of the neutron spectrum as given by the Westcott ${ }^{(5)}$ model. This model characterizes the neutron spectrum as well thermalized and consisting of two components, a Maxwellian and a $1 / E$ distribution. Basically, the recipe codes are fitted calculations of the four-factor parameters $(n, f, p, \varepsilon)$ and the diffusion parameters $\left(D, L^{2}, \tau\right)$, based on semi-empirical procedures. 
Some typical recipes are the Swedish recipe BURNUP, ${ }^{(6)}$ and a more recent version REBUS, ${ }^{(7)}$ the Canadian recipe LATREP, ${ }^{(8)}$ the Euratom code PLUTHARCO, ${ }^{(9)}$ and the codes BSQ, ${ }^{(10)}$ ROCKLAND A, ${ }^{(11)}$ NDC, (12) and IDIOT, (13) developed in the U.S. by Savannah River, United Nuclear, Westinghouse, and Hanford, respectively. The major limitation of recipes, which was recognized early in the development of $\mathrm{D}_{2} \mathrm{O}$ reactor physics, is that they have a limited range of applicability. Each recipe is adjusted to fit a certain range of lattices of a particular design, and cannot be applied successfully outside this range.

An alternative to the classical recipe approach has been the adaptation of the multi-group codes developed for designing $\mathrm{H}_{2} \mathrm{O}$ reactors. These codes consider the neutron processes in the lattice in great detail, and their use constitutes a much less empirical and more fundamental calculational approach than the use of recipes.

An example of an early use of this approach is the analysis of the CVTR experiments by Westinghouse ${ }^{(14)}$ in the early 1960's. The

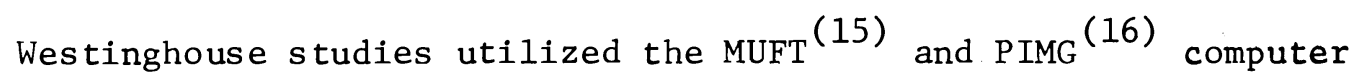
codes for the slowing down calculation, with an auxiliary Monte Carlo calculation with the REPLICA ${ }^{(17)}$ code to provide self-shielding factors for MUFT; THERMOS ${ }^{(18)}$ for the thermalization calculation; and the two-dimensional diffusion theory code PDQ ${ }^{(19)}$ for the reactor calculation. This approach of adapting light water codes to heavy water lattices, lead surprisingly to fairly good success.

The panel report ${ }^{(2)}$ on Heavy Water Lattices, held in Vienna in February of 1963, contained status reports of the $\mathrm{D}_{2} \mathrm{O}$ reactor physics efforts of many nations. One of the points made at this panel 
meeting (20) was that the recipe-type codes, while very useful, had limited areas of applicability. It was predicted that recipes would remain as important tools for $\mathrm{D}_{2} \mathrm{O}$ reactor designers, but at the same time there would be an ever-increasing trend toward very detailed calculations.

The trend toward more fundamental calculational methods was illustrated by the Westinghouse CVTR analysis, ${ }^{(14)}$ and also with the use of the two British codes, METHUSELAH ${ }^{(21)}$ and THULE, (22) introduced at the 1963 Panel Meeting. Both of these codes had been developed in support of the Steam Generating Heavy Water Reactor. The METHUSELAH code was meant to be a design code and was modeled after a four-group diffusion theory scheme of the Bettis Laboratory of Westinghouse. METHUSELAH, however, is a five-group scheme, with two overlapping thermal groups, one characteristic of the moderator region and the other characteristic of the fuel region. The code THULE represented the most exact calculation feasible at the time, and was developed and used to check the validity of METHUSELAH calculations. The THULE code, which was built around the existing multi-group Carlson Transport Theory Code DSN, ${ }^{(23)}$ was basically a multi-group transport calculation in cylindrical geometry, with some Monte Carlo assistance in the resolved resonance region. The introduction of the THULE code was a big step in the direction of basing $\mathrm{D}_{2} \mathrm{O}$ lattice calculations on truly fundamental methods.

B. Cell calculations Development

1. U.S. Methods

An extensive comparison of calculations and experiments was presented in a 1964 review article by Honeck and Cranda11. (4) 
An extensive calculational study of single-rod uniform lattices was presented in the review. In this study the computer codes THERMOS ${ }^{(18)}$ and FORM ${ }^{(24)}$ were used to generate few group constants, and the experimental buckling was used to describe leakage in computing $\mathrm{k}_{\mathrm{eff}}$. The calculations proved to match the experiments extremely closely and an immediate development program was undertaken by Honeck and J. E. Suich, of Savannah River Laboratory, to automate the process in a single computational code.

The result was the HAMMER ${ }^{(25)}$ code which has since become the standard code for heavy water lattice calculations in many of the U.S. laboratories, and more recently has been adapted also to the Chalk River computers. Although the code retains many approximations it is basically a first-principles method, working directly from the reactor geometry and material cross sections without any empirical fitting factors. Calculations are made in 84 energy groups, 30 in the thermal neutron energy region (THERMOS) ${ }^{(18)}$ and 54 in the epithermal region (MUFT), ${ }^{(15)}$ using integral transport methods. Resonance cross sections in the epithermal region are determined by built-in side calculations through the ZUT and TUZ codes. (26) Excellent agreement has been obtained ${ }^{(27)}$ between this code and over 100 experiments performed on single rod and tubular fuel lattices in laboratories all over the world. This agreement supplies adequate proof that HAMMER is capable of providing good calculations for uranium- $\mathrm{D}_{2} \mathrm{O}$ lattices with simple fuel geometry. However, HAMMER is at present a one-dimensional code, and can treat fuel clusters only in terms of simplified cylinderized models. These models have the disadvantage of not being able simultaneously 
to reproduce the correct material areas, the cluster size, the fuel surfaces, and the scattering paths. Another major limitation of the HAMMER code is its inadequate resonance treatment, specifically the use of the narrow resonance approximation for moderator and coolant, the neglect of resonance overlap effects, and the assumption of a flat flux in the resonance energy region. Recent comparisons between HAMMER calculations and fuel cluster experiments show appreciable differences. In spite of its limitations, the HAMMER code represents the state-of-the-technology of $\mathrm{D}_{2} \mathrm{O}$ reactor physics calculations in the United States. Some work has been done under a USAEC-AECL cooperative program toward developing a two-dimensional version of HAMMER, specifically for fuel cluster calculations.

Another calculational scheme which represents the approach of adapting codes developed for $\mathrm{H}_{2} \mathrm{O}$ lattices, is that developed by Battelle-Northwest. This scheme is similar to HAMMER in that it uses the THERMOS code for the thermalization calculation, but differs from HAMMER in that it uses the code HRG ${ }^{(28)}$ (Hanford Revised GAM) for the slowing-down calculation. The HRG-THERMOS scheme, coupled with a diffusion theory reactor calculation, has been applied at Battelle-Northwest with a fair degree of success to plutonium-fueled $\mathrm{D}_{2} \mathrm{O}$ reactors.

\section{Foreign Methods}

In recent years in Britain the THULE program has led to the development of the Winfrith Improved Multi-group Scheme, WIMS. The options incorporated in the WIMS code allow the calculation 
of simple lattices with any moderator, as well as complex cluster systems with either gas channels or liquid coolants. It is a highly flexible code allowing either elaborate calculations in many groups or more rapid computations in few groups for design purposes. The geometry of a cluster cell can be represented by either concentric rings or an explicit collision probability method which allows a detailed representation of cluster geometries. The treatment of resonances in WIMS differs from that in THULE ${ }^{(22)}$ which required expensive Monte Carlo calculations. The resonance treatment in WIMS is based on equivalence theorems which relate a library of resonance integrals for each resonance absorber in each group to the particular heterogeneous problem. It takes account of source-depletions within groups caused by the resonance absorption, and account of resonance interaction effects. A number of methods are available to modify the infinite lattice results to include leakage in a finite reactor. Both diffusion and transport theory calculations may be performed. The accuracy of the approximations used in WIMS have been checked quite exhaustively by Monte Carlo and other basic methods.

The Swedish, who have traditionally relied heavily on recipes, have in recent years shown an interest in integral transport theory calculations. The most sophisticated calculational code they are using currently is FLEF, ${ }^{(30)}$ which is a version of the British WIMS ${ }^{(29)}$ code.

At Ispra, Italy, Euratom has developed the code PINOCCHIO, (31) which is of approximately the same order of sophistication as 


\begin{abstract}
HAMMER. (25) They are working on a two-dimensional representation of clusters for the THERMOS portion of PINOCCHIO.

It is obvious from the above that in recent years there has been a world-wide trend away from recipe methods and toward more sophisticated calculational methods.
\end{abstract}

C. Basic Data and Methods Used in Calculations

As the calculational methods become more refined, and as they are based more and more on basic principles, the need for accurate cross section information, slowing down theory, and scattering kernels becomes more acute. The following reviews present the state-of-thetechnology in these areas of basic data and methods.

1. Cross Sections (Contributed by B. R. Leonard, Jr. and R.C. Liikala)

Many of the cross sections used today were prepared in the late 1950's and have never been updated. In some cases, these data are still the best available, but in most cases better data exist. Furthermore, new measurements are being made at an increasing rate. Before the data can be utilized in the reactor calculation, the experimental data must be evaluated into point cross-section sets, and the point cross-section sets processed into multi-group sets. This causes an appreciable delay between measurement of the data and utilization.

The USAEC has initiated an intense national effort to reduce the delays. New evaluated point cross-section sets have been and are being prepared, and placed in a uniform format known as the ENDF/B system. (55) The work is being done under the 
direction of the Cross Section Evaluation Working Group, whose members represent some eighteen AEC contractors, the Cross Section Evaluation Center at BNL, and some other interested laboratories. A number of computer codes have been developed to process the ENDF/B data into multi-group sets. Many of these codes are now operational and multi-group sets are being generated. Included in the ENDF/B data are thermal scattering laws for most of the materials used in heavy water reactors. This collection of data will make it possible to explicitly compare calculational methods used at various laboratories by using this set of basic nuclear data with the various methods.

A brief review of the thermal and resonance cross sections for some of the fissile and fertile nuclides important to $\mathrm{D}_{2} \mathrm{O}$ reactors are given here.

a. Thermal. The precision of the knowledge of the thermal cross section values of plutonium historically has been inferior to that of uranium. The evaluations of $2200 \mathrm{~m} / \mathrm{sec}$ values for ${ }^{232}$ Th and ${ }^{238} \mathrm{U}$ are generally within the band of uncertainty $\pm 2 \%$. Only two precise monoenergetic measurements exist of the $2200 \mathrm{~m} / \mathrm{sec}$ absorption cross section of ${ }^{240} \mathrm{Pu}$ and these differ by $5.4 \%$. Precisions in the fundamental values of $\eta$ and $\alpha$ for plutonium 239 and 241 are factors of $\sim 5$ worse than for uranium 233 and 235. Additional and related uncertainties are present in calculating reaction rates in reactor spectra for systems containing plutonium because of a significantly non-1/v behavior of the thermal cross section of the principal fissile isotopes, ${ }^{239} \mathrm{Pu}$ and ${ }^{241} \mathrm{Pu}$. 
Various adjustments in the $2.200 \mathrm{~m} / \mathrm{sec}$ values of the major fissile-nuclide constants have been made since 1961. At the present time, the IAEA is sponsoring another adjustment which will incorporate the results of a dozen or so measurements completed since the last evaluation in 1965. The adjustment is expected to be completed in the spring of 1969 . While the forthcoming adjusted constants will probably be the best estimate of the values at that time the precisions which will be assigned should be carefully considered.

One of the most promising approaches to improving the knowledge of the cross section values of the fissile nuclides is a study of spectrum-averaged or effective cross-section measurements with modern calculational methods. In the past such experiments have been almost universally interpreted in terms of the Maxwellian thermal spectrum. The uncertainties due to deviations from a Maxwellian shape are not assessed in such an interpretation. In addition, there exists the related uncertainty of compounding the error by using $2200 \mathrm{~m} / \mathrm{sec}$ values derived on the assumption of a Maxwellian shape and then calculating reaction rates using calculational codes which do not assume a Maxwellian spectrum.

b. Resonance. The uncertainty in the resonance cross sections for ${ }^{232} \mathrm{Th},{ }^{238} \mathrm{U}$, and ${ }^{240} \mathrm{Pu}$ is perhaps no greater than $5 \%$. The calculated values of the resonance integrals for infinite dilution based upon differential cross sections when compared 
to directly measured values generally agree to within $\pm 4 \%$ for ${ }^{232}$ Th and ${ }^{238} \mathrm{U}$ and about $\pm 5 \%$ for ${ }^{240} \mathrm{Pu}$. However, calculated resonance integrals for ${ }^{238} \mathrm{U}$ based upon differential data are consistently lower than directly measured values (i.e., calculated $\sim 270$ b, measured $\sim 282$ ). The complexity of the resonance structure for these nuclides adds to the uncertainty in calculating the reaction rates in thermal reactors, with the ${ }^{240}$ Pu reaction rate being the most difficult to calculate.

Additional efforts are needed to put this technology on firm ground. The systematic difference between measured and calculated values of the ${ }^{238} \mathrm{U}$ resonance integral needs to be resolved. More monoenergetic measurements of the ${ }^{240} \mathrm{Pu}$ cross sections are desirable.

\section{Slowing Down Treatment in Heavy Water Reactors (Contributed by}

J. L. Carter, Jr.)

Many of the epithermal calculations for $\mathrm{D}_{2} \mathrm{O}$ systems have been done with the MUFT ${ }^{(15)}$ code, or others based on its technique. Briefly, this technique solves the $B_{1}$ or $P_{1}$ version of the homogenized Boltzmann transport equation, using the auxiliary concept of slowing down density. Slowing down by hydrogen is treated exactly and slowing down by other atoms may be treated by the Greuling-Goertzel ${ }^{(56)}$ method. Corrections for resonance absorption are made using a form for resonance integrals derived for unbroadened resonances in a homogenized system, but with the possibility of modifying some of the parameters to allow 
for heterogeneity and Doppler broadening to a low order of approximation. The technique was derived originally for use in $\mathrm{H}_{2} \mathrm{O}$ systems, for which the approximations are more valid than for $\mathrm{D}_{2} \mathrm{O}$ systems. In practice, the technique has proved quite acceptable for both systems, ${ }^{(4)}$ especially when calibrated to study variations of a specific concept.

Although the Greuling-Goertzel method is a great improvement over Fermi age theory for deuterium, it gives only a rough description of the scattering properties of deuterium. Since the resonance treatment in MUFT is also quite approximate, the overall success of the analysis of $\mathrm{D}_{2} \mathrm{O}$ systems, using MUFT for the epithermal region, may be attributed to two factors: the subordinate role the epithermal region plays in such systems and a fortuitous balancing of approximation errors. Though this success is encouraging for the adequacy of further calculations on similar systems, doubts arise as to the accuracy of calculations on different, and more complex systems, for example those using plutonium as fuel, light water as coolant, and heavy water as the moderator. Comparison of results obtained using the MUFT technique with those obtained using difficult and improved techniques seem indicated.

Several epithermal spectrum codes already exist which use techniques different from, and improved upon, the MUFT technique. The epithermal portion of the HAMMER ${ }^{(25)}$ system uses the MUFT slowing down technique in a heterogeneous calculation based on integral transport theory and has an improved resonance 
treatment which includes heterogeneity and Doppler broadening effects. The GAM-I, (57) GAM-II and HRG ${ }^{(28)}$ (an improved version of the GAM-I) codes, use a full scattering transfer matrix, rather than the Greuling-Goertzel approximation, in solving the $B_{1}$ or $P_{1}$ version of the homogenized Boltzmann transport equation. Treatment of resonances in these codes is by the Adler-Nordheim ${ }^{(58)}$ technique and includes heterogeneity and Doppler broadening. A comparison of analyses of simple $\mathrm{D}_{2} \mathrm{O}$ systems using the different techniques of HRG and HAMMER would evaluate two different approaches to treating slowing down and resonance absorption. To be significant, the comparison should be made using nuclear data from the same compilation, e.g., the BNW Master Library or the ENDF/B ${ }^{(55)}$ data system.

3. The Experimental Scattering Law for Heavy Water -

(contributed by 0. K. Harling)

a. Introduction

In order to carry out thermalization calculations, energy transfer cross sections must be known for a comprehensive grid of energy and momentum changes. Measurements are made of the double differential cross section $\sigma\left(E_{0} \rightarrow E_{1}, \theta\right)$ which is related to the scattering law, (59) $\mathrm{S}(\alpha, \beta)$ by the following relations,

$$
\begin{aligned}
& S(\alpha, \beta)=\frac{d^{2} \sigma\left(E_{o} \rightarrow E_{1}, \theta\right)}{d \Omega d E} \frac{4 \pi k T}{\sigma_{b}}\left(E_{o} / E_{1}\right)^{1 / 2} \ell^{\beta / 2} \\
& \alpha=(\Delta \bar{P} / 2 M k T)^{2}=\frac{m\left[E_{o}+E_{1}-2\left(E_{o} E_{1}\right)^{1 / 2} \cos \theta\right]}{M k T} \\
& \beta=\frac{E_{1}-E_{o}}{k T}
\end{aligned}
$$


where $E_{0}$ and $E_{1}$ are the final and initial neutron energies, $\theta$ is the scattering angle, $m$ is the neutron mass, $M$ is the mass of the principal scattering atom, $\mathrm{k}$ is Boltzmann's constant and $\mathrm{T}$ is the absolute temperature. Experimental determinations of $\sigma\left(E_{0} \rightarrow E_{1}, \theta\right)$, generally provide results for a limited range of momentum and energy changes. Since there is frequently no rapidly varying structure in the cross sections for moderators, simple interpolation can often be used to provide a more comprehensive grid in $\Delta \mathrm{P}$ and $\Delta \mathrm{E}$. However, it is desirable to develop a scattering law or scattering kernel which can provide slowing down cross sections for any value of energy and momentum transfer for the entire range of these variables which is of interest in thermalization problems. This can often be done with the aid of theoretical models which have been adjusted to fit experimental results over the limited ranges in which the data are available. The status of the $\mathrm{D}_{2} \mathrm{O}$ scattering law will be discussed here with reference to the type and coverage of existing experimental results, the consistency and accuracy of results, possible sources of errors in measurements and comparison of experimental scattering law with results from model calculations.

b. Experimental Cross Sections for $\mathrm{D}_{2} \mathrm{O}$

Double differential cross sections measurements using the slow neutron downscattering technique, provide the most extensive sets of measured slowing down cross sections. Several experimental studies of this type have been made on $\mathrm{D}_{2} \mathrm{O}$. 
Haywood $^{(60)}$ used a phased multiple rotor chopper to measure the scattering 1 aw for $295^{\circ} \mathrm{K}$ and $423^{\circ} \mathrm{K}$ heavy water with beta values to -3 and $\alpha$ values to $\sim 6$. Using the same spectrometer Page ${ }^{(61)}$ has measured the scattering law for a $540^{\circ} \mathrm{K}$ heavy water sample and has published a compilation which includes $S(\alpha, \beta)$ values for $\beta$ to -1.85 and $\alpha$ values to $\sim 5$. Harling ${ }^{(62)}$ has reported measurements of the scattering law for $299^{\circ} \mathrm{K} \mathrm{D}_{2} \mathrm{O}$, using a rotating crystal spectrometer, with $\beta$ values to -7.5 and $\alpha$ 's to 15. High energy transfer measurements at $294^{\circ} \mathrm{K}$, using an electron linear accelerator have been reported by Whittemore, with $\beta$ values to -25 and $\alpha$ values to $\sim 40$.

In experimental results of this type, involving complex measuring technique, the question of accuracy is an important one. This is especially true in the case of moderator scattering laws since the data may be used to predict neutronics behavior of expensive reactor systems. One good measure of the quality of experimental results is the consistency of results from a single laboratory. Where measurements of the same quantity have been obtained by different investigators and laboratories a better test of accuracy is to compare these independent results.

A measure of the existing accuracy in the measured room temperature scattering law for $\mathrm{D}_{2} \mathrm{O}$, can be obtained by comparing the independent results of Haywood, ${ }^{(60)}$ Whittemore ${ }^{(63)}$ and Harling. (62)(93)

It is clear that substantial differences exist between the various sets of data and in some cases there is also considerable dispersion within a single set of data. Near the peaks 
of the $s(\alpha, \beta)$ curves the total spread in $S$ values is approximately 58, 38, 19 and 33\% respectively for the curves at $\beta=1,3,5$, and 7 . The mean total spread is $\sim 37 \%$. Somewhat larger spreads occur at the low and high $\alpha$ ends of the data sets. With a view toward ultimate use in reactor thermalization calculations a better gauge of the consistency between separate sets of experimental data might be to fit smooth curves to each set of data and then obtain a mean by averaging the separate curves. This tends to smooth out any fine structure in $\alpha$ but should be satisfactory for the thermalization kernel in the case of $\mathrm{D}_{2} \mathrm{O}$. Using this procedure to obtain several average data points near the peaks of the $S$ curves we find mean values which have an rms deviation of about $23,4,7.5$ and $5 \%$, respectively for the curves with $\beta=1,3,5$, and 7 . This magnitude of spread in $S$ for measurements taken at different laboratories is representative of the present state of the art in measurements of this type. Approximately the same degree of inconsistency is found in room temperature light water measurements at this time. $(62,64,65)$

Extensive results for $S(\alpha, \beta)$ at elevated temperatures are available only from one laboratory, the Atomic Energy Establishment, Harwell, England. $(60,61)$ The scatter of the individual data points is within about $25 \%$ for the various measurements. c. Source of Error in Experimental Results

The experimental results are subject to a number of sources of error. The most important of these are believed to be: 

a) Statistical counting errors
b) Resolution effects
c) Multiple scattering
d) Various systematic errors

The counting statistics are easy enough to determine during the reduction of the raw data to cross sections. This error is usually small compared to the scatter of the data from the various experiments. Also, the randomness of direction of this error insures that there is no systematic bias in the results and all one needs to do to make this error small is to obtain sufficient measurements or counts.

Resolution effects are of two types, those due to resolution in angle and those due to energy resolution. The former affects the structure in momentum transfer and is not generally important for moderator materials with the commonly utilized counter solid angles. The energy resolution is, however, an important factor. In general, for a time-of-flight (TOF) spectrometer the resolution on energy transfer is strongly dependent upon the energy transfer. For a given initial energy the largest energy transfers are measured with the best resolution while small energy changes have the worst resolution. The situation is particularly bad near the quasielastic peak in the scattered neutron spectrum. In principle it is possible to remove the quasielastic scattering peak from the downscattered spectrum. However, this is difficult to do with the required accuracy. In practice it is highly desirable 
to design the experiments to provide data for over-lapping energy transfers. When this is done it is possible to choose the data for a given $\beta$ value which is least likely to be subject to resolution broadening or other sources of error, e.g., multiple scattering which will be discussed below. The presently available data on $\mathrm{D}_{2} \mathrm{O}$ has probably been taken with adequate energy resolution to produce an adequate scattering kernel, with the possible exception of very low energy transfer data. The results cited above were not obtained with good resolution in the region of $\beta$ from $\sim 0$ to $\sim .5$. Cold neutron upscattering experiments with beryllium filtered neutrons have potentially very good resolution in this low energy transfer region and could be used to supplement the downscattering results. Measurements of this type have been made on $\mathrm{D}_{2} \mathrm{O}$ by Larsson and Dahlborg. (66)

The multiple scattering of neutrons with the "typical" samples produce errors in the scattering distributions which are expected to vary from fractionally large to fractionally negligible, depending upon the $\alpha$ and $\beta$ value at which the neutron is observed and upon the scattering properties or true scattering law for the sample. It has been found by Slaggie ${ }^{(67)}$ that even with relatively high transmission the multiply scattered flux in $\mathrm{H}_{2} \mathrm{O}$ experiments can account for a large fraction of the measured cross sections, e.g., $\sim 30 \%$ for some values of $\alpha$ and $\beta$. The largest corrections apply for small momentum transfers and large values of energy transfer. The Slaggie computational 
scheme for water is based on an incoherent scatterer and therefore is not necessarily applicable to $\mathrm{D}_{2} \mathrm{O}$ which has a primarily coherent scattering cross section. However, recent work by Haywood and Page ${ }^{(68)}$ and by Harling ${ }^{(69)}$ indicates that scattering from $\mathrm{D}_{2} \mathrm{O}$ can be well described without explicit attention to coherence effects. Therefore, the multiple scattering corrections calculated by Slaggie for light water are probably reasonable estimates of the same effect in $\mathrm{D}_{2} \mathrm{O}$. In view of the magnitude of the multiple scattering corrections and the sensitivity of the effect to experimental parameters like sample thickness, initial and final energy and scattering angle, a really good comparison of presently available data is not possible. It seems desirable, therefore, to make the best possible multiple scattering corrections to the available data before these are used to derive a state-of-the-art scattering kernel for $\mathrm{D}_{2} \mathrm{O}$.

Various other sources of error may be present in double differential cross section results. These include errors due to background subtraction, in normalization to obtain absolute cross sections, the detector response function, contamination of the incident beam, air scattering in the detector flight paths, uncertainties in the sample composition or size and various instrumental problems which occur in almost every experiment. In general, it should be possible to make the influence of these factors small compared to the effects of multiple scattering or resolution effects. However, there is always a possibility that a systematic source of error may 
occur which is either inadequately corrected or which is not recognized at all.

d. Experimental Results Compared with Model Calculations

Various models have been developed to calculate the scattering from $\mathrm{D}_{2} \mathrm{O}$. One of the best tests of the accuracy of such a model is to use it to calculate cross sections which can be compared to experimental values. In doing this it should be remembered that the experimental results are in some cases subject to substantial sources of error. Two models which have been moderately successful in predicting the scattering properties of $\mathrm{D}_{2} \mathrm{O}$ are: 1) the McMurry-Russel1 (70) model for water which is a refinement of the Nelkin ${ }^{(71)}$ model and which has been adapted to heavy water, ${ }^{(72)}$ and 2) a model based on the theoretical approach of Egelstaff and Schofield (73) which uses an incoherent theory with a Gaussian approximation to the self-correlation. In the Egelstaff-Schofield theory the scattering law is calculated from a multiphonon expansion using the computer program LEAP ${ }^{(74)}$ and a spectral density function which can be derived from experiments or from theoretical considerations.

The rather large difference between the theoretical scattering law values and the experimental results at small $\alpha$ values is disturbing and indicates a need for an understanding regarding its source. It would be desirable to make corrections to the data for multiple scattering and resolution effects. The influence of coherence should also be considered. Butler (75) 
4. Scattering Kernels for Heavy Water (contributed by Alan G. Gibbs)

a. Introduction

When slow neutrons interact with a system of atoms, the interactions require sufficient time for the neutrons to sense not only the presence, but also the velocities and accelerations of the individual atoms. Thus both scattering and absorption cross sections for slow neutrons depend intimately on the detailed dynamics of the atomic motions.

The dynamics of even an isolated $\mathrm{H}_{2} \mathrm{O}$ or $\mathrm{D}_{2} \mathrm{O}$ molecule is complex, since the molecule as a whole can experience both translation and rotation, while the individual atoms can participate collectively in three independent vibrational modes. All of these degrees of freedom may be involved to some extent when a neutron is scattered by the molecule. The situation is further complicated in problems of practical interest, since the molecules are not isolated but occur in water or ice. Here the interactions between neighboring molecules lead to a highly complex mutual hindrance of their translational and rotational motion. A precise description of this process is, of course, not available, and calculations of scattering cross sections must be based on greatly simplified models which (hopefully) retain the essential features of the actual systems. Some important simplifications occur in describing scattering by $\mathrm{H}_{2} \mathrm{O}$ which do not occur in $\mathrm{D}_{2} \mathrm{O}$. When neutron waves are scattered by any atomic nucleus the phase shift 
and Koppel and Young ${ }^{(76)}$ have shown that there is some cancellation in the coherent scattering but that these effects are still likely to be important in the partial cross sections at sma11 $\alpha$ and $\beta$.

e. Summary

Extensive room temperature data exist for the scattering kernel of $\mathrm{D}_{2} \mathrm{O}$. Before averaging the results from the separate laboratories to produce a state-of-the-technology scattering kernel, corrections must be applied to the data. Especially important is the question of multiple scattering for which large corrections may be necessary.

Experimental results for $\mathrm{D}_{2} \mathrm{O}$ scattering at elevated temperatures, are available only for a limited range of energy and momentum transfers. Presently available measurements do not include the energy transfer range of the intramolecular vibrations which become more important in the thermalization problem, the higher the moderator temperature. Also, the elevated temperature results are from only one laboratory and there can be substantial differences between results from different laboratories. Thus, there is a need for extensive measurements of the scattering law for $\mathrm{D}_{2} \mathrm{O}$ at the highest practical temperatures. Such experiments should be designed to provide a kernel for the entire range of bound deuteron motions. Corrections for multiple scattering and other effects should, of course, be made to the elevated temperature data. 
depends on the relative alignment of the neutron and nuclear spins. For hydrogen the phase shifts are of opposite sign, with the fortuitous result that coherent scattering is not significant in $\mathrm{H}_{2} \mathrm{O}$. The restriction to incoherent scattering means that only a description of the dynamics of single atoms is needed to calculate the scattering cross sections. (As shown by Van Hove, $(77)$ coherent scattering - which is significant in $\mathrm{D}_{2} \mathrm{O}$ - depends on the correlated dynamics of pairs of atoms, and is thus much more difficult to calculate.) A further simplification occurs in $\mathrm{H}_{2} \mathrm{O}$ because the hydrogen cross section is much larger than the oxygen cross section, and thus oxygen scattering can be neglected or treated approximately.

Present models for $\mathrm{D}_{2} \mathrm{O}$ use modifications of models first proposed for $\mathrm{H}_{2} \mathrm{O}$, to calculate the incoherent contribution to the scattering. Thus it will be convenient to begin with a review of $\mathrm{H}_{2} \mathrm{O}$ kernels. All critical comments in this section will, of course, apply equally well to the incoherent part of the corresponding $\mathrm{D}_{2} \mathrm{O}$ kernel.

b. $\mathrm{H}_{2} \mathrm{O}$ Kernels

Several models have been proposed to describe the motion of hydrogen in water. The earliest such model, also applied to other moderators, assumes that the hydrogen moves as in a free gas, ${ }^{(78)}$ and all chemical binding effects are ignored. Since this model does not reproduce the measured total cross section of $\mathrm{H}_{2} \mathrm{O}$, a modification has 
been suggested by Brown and St. John. (79) The free gas behavior is retained, but the dependence of the cross section on the neutron-nucleus relative velocity is assumed to be given by a (non-physical) sum of exponentials, with the parameters chosen to fit the measured total cross section. While both of these gas-like models have been applied to $\mathrm{H}_{2} \mathrm{O}$, they are now generally conceded to be inadequate at thermal energies because of their complete neglect of interactions between neighboring atoms.

The first model which seriously attempted to describe the motion of hydrogen in water was proposed by Nelkin (71) in 1960. In the Nelkin model, it is assumed that each molecule has the same internal vibrational modes that occur in the vapor state. In addition, it is assumed that the hindered rotational motion of the entire molecule can be represented as a harmonic torsional oscillation at a single frequency. The hindered translational motion is assumed to involve oscillations at frequencies so low that neutrons cannot distinguish the molecular translations from those of a free gas. Thus the Nelkin model proposes in essence that $\mathrm{H}_{2} \mathrm{O}$ resembles a harmonic crystal having a normal mode distribution consisting only of delta functions, one at $\hbar \omega=0$ (translation), one at $\hbar \omega=.06 \mathrm{eV}$ (hindered rotation), one at $\hbar \omega=0.205 \mathrm{eV}$ (vibration), and one at $\hbar \omega=0.481 \mathrm{eV}$. (representing the two closely spaced high energy vibrational modes). In spite of the planar nature of the water molecule, 
the Nelkin model treats each of the above frequencies as a symmetric harmonic oscillator and evaluates the cross section using the general result of Zemach and Glauber ${ }^{(80)}$ for a system of symmetric harmonic oscillators.

The anisotropic nature of the molecular vibrations is considered in an extension of the Nelkin model proposed by Koppel and Young ${ }^{(81)}$ in 1964. Their frequency spectrum also consists of four delta functions, but now the relative weights depend on the orientation of the molecule with respect to the neutron, and the scattering cross section is obtained by averaging the results (numerically) over orientations. While this model predicts infinite medium spectra in closer agreement with experiment than does the Nelkin model, it has not been used widely, probably because of the substantial increase in computation time. Finally, it should be noted that more recent calculations by McMurry and Russell ${ }^{(65)}$ using the same model give somewhat different values for the total cross section than those reported by Koppel and Young. This difference has not yet been resolved.

McMurry and Russel1 (65) (MR) have also proposed another extension of the Nelkin model. While retaining the assumption of isotropic harmonic vibrations, they admit that the motion of hydrogen in water is too complex to be described by four discrete frequencies alone, and use a frequency spectrum consisting of twenty delta functions. 
They retain the translational and vibrational modes of the Nelkin model while replacing the single hindered rotational frequency by seventeen new frequencies. MR interpret these frequencies as being due to rotations of both free molecules and aggregates of many molecules, and to internal vibrations of aggregates of molecules. (While this interpretation aids in the selection of the parameters of the model it does not seem to be essential for the use of a twenty-delta function frequency spectrum.) For simplicity, MR assume that the aggregates consist of either 75 or 150 molecules. MR report very good agreement between their model and experiment for the total cross section, and considerable improvement over the Nelkin model in the average cosine of the scattering angle.

The models of Nelkin, Koppe1-Young, and MR al1 treat water as a quasi-crystalline substance characterized by a frequency spectrum. This is of course only an approximation to a real liquid, for which the distribution of normal modes is not even defined. The concept of a frequency spectrum can nontheless be defined for a general dynamical system in terms of the Fourier transform of the velocity autocorrelation function. For a solid the frequency spectrum is identical to the normal mode distribution, while for a liquid only the former is defined. For a harmonic crystal, the scattering is completely determined by the frequency spectrum $\rho(\beta)$, but for a liquid this not the case. An 
approximate expression for the scattering cross section of a liquid, involving only $\rho(\beta)$, can be given and is known as the Gaussian approximation. It was first proposed by Vineyard ${ }^{(82)}$ and has been further developed by Egelstaff and Schofield. (59)

All of the above models can now be seen to be equivalent to the use of the Gaussian approximation with the actual frequency spectrum approximated by a series of delta functions. (Even the ideal gas model is such an approximation with the frequency spectrum replaced by a single delta function at zero frequency.) As an alternative to such models, Egelstaff and Schofield ${ }^{(59)}$ have shown how the actual frequency spectrum can be obtained from experimental scattering data. If a precise determination of $\rho(\beta)$ were possible by this method there would clearly be little further need for the simplified models discussed above. However, in practice considerable complications arise from coherent effects and (particularly) multiple scattering which lead to large uncertainties in the measured $\rho(\beta)$. These difficulties have not yet been overcome, although many approximate measurements of $\rho(\beta)$ for $\mathrm{H}_{2} \mathrm{O}$ have been reported in the literature, the most recent (and presumably best) being those of Haywood ${ }^{(84)}$ and Harling. (85)

Improved techniques for multiple scattering corrections will no doubt make more precise determinations of $\rho(\beta)$ possible in the future. The eventual limitations on the 
accuracy of the scattering kernels obtained from $\rho(\beta)$ will thus depend on the (presently not well known) dynamic effects ignored by the Gaussian approximation. However, as reported by Honeck $(86)$ the best present kernels are already considered to be adequate for use in reactor design. (While presenting his paper, Honeck remarked that this statement was intended to apply to $\mathrm{U}^{235}$ systems; for Pu systems the low-1ying resonance necessitates a more precise description of the epithermal spectrum, and thus requires a more sophisticated scattering kernel.) Thus, while more accurate determinations of $\rho(\beta)$ are certinaly desirable, consideration of the more subtle non-Gaussian effects will probably not be necessary for $\mathrm{H}_{2} \mathrm{O}$.

c. $\mathrm{D}_{2} \mathrm{O}$ Kernels

We have already remarked that neutron scattering by $\mathrm{D}_{2} \mathrm{O}$ is complicated by significant contributions from interference scattering and from scattering by the oxygen. In seeming defiance of these facts, Honeck ${ }^{(87)}$ has proposed that the Nelkin model, with some slight modifications in the vibrational and rotational frequencies, be applied directly to $\mathrm{D}_{2} \mathrm{O}$. The oxygen contribution to the total cross section is taken to be a constant, independent of energy, while the coherent effects are neglected completely! Honeck justifies this neglect by pointing out that Placzek ${ }^{(88)}$ has shown that the first energy transfer moment of the interference scattering is always zero, while the contribution of interference 
scattering to the total cross section oscillates about zero, with a small amplitude at higher energies. Thus the energy transfer moments of the cross section should not contain large contributions from interference scattering. Honeck's calculated total cross section is indeed in good agreement with experiment for $\mathrm{E}>.01 \mathrm{eV}$, although it is high by a factor of about 2 for $\mathrm{E}<.001 \mathrm{eV}$. In addition, Honeck calculates diffusion and diffusion cooling coefficients for $\mathrm{D}_{2} \mathrm{O}$, and obtains numbers agreeing (within experimental accuracy) with the results of pulsed neutron experiments; however, he speculates that quantities sensitive to the higher angular moments of the cross section will not be correctly predicted by his model.

The role of interference scattering in $\mathrm{D}_{2} \mathrm{O}$ is investigated further in the work of Butler ${ }^{(75)}$ and Koppel and Young. (76) Butler assumes the same four-frequency dynamical model of the $\mathrm{D}_{2} \mathrm{O}$ molecule suggested by Honeck, but uses the general formalism of Zemach and Glauber ${ }^{(80)}$ to evaluate both the incoherent, and the intra-molecular interference contributions to the cross section. In addition, he obtains the inter-molecular interference contribution from a simple model in which atoms in different molecules are assumed to appear as randomly distributed, stationary hard spheres. This model is admittedly crude, but is perhaps all that is warranted in the absence of a more detailed knowledge of the interactions and resulting complex, time-dependent, 
correllated dynamics of pairs of molecules in a liquid. The use of the stationary approximation does find some justification in the experimental observation of Brockhouse ${ }^{(89)}$ of a peak of approximately elastically scattered neutrons in $\mathrm{D}_{2} \mathrm{O}$ which does not occur in $\mathrm{H}_{2} \mathrm{O}$ : the stationary approximation does lead to an elastic peak. Some numerical results are given by Butler to display the relative contributions of the incoherent, and the intraand inter-molecular interference scattering to the cross section.

Extensive calculations based on Butler's model are reported by Koppel and Young, ${ }^{(76)}$ who also correct some numerical errors made in Butler's original work. Only a summary of their conclusions will be given here:

1. Interference scattering is important primarily for small energy and momentum transfers.

2. In the total cross section, the intra- and intermolecular interference terms are of opposite sign and nearly cancel. Thus for $\mathrm{E}>.004 \mathrm{eV}$ the total cross section is well-represented by the incoherent part alone (as observed by Honeck). If interference effects are included, the present model is adequate to calculate the total cross section down to $\mathrm{E}=.002 \mathrm{eV}$.

3. The average cosine of the scattering angle is wellrepresented by the incoherent contribution alone for $\mathrm{E}>0.1 \mathrm{eV}$; however, interference effects are important at lower energies. 
4. The angular-dependent cross section (integrated over energy) shows considerable structure due to interference effects, and is in general agreement with the experimental results obtained by springer ${ }^{(90)}$ and by General Atomic.

The above conclusions indicate that at least infinite medium spectra will be predicted adequately by an incoherent scattering model except at very low energies. Thus there is considerable justification for considering improvements of the Honeck-Nelkin model to better calculate the incoherent contribution to the cross section.

Recently, McMurry ${ }^{(72)}$ has proposed that a modification of the MR model be applied to $\mathrm{D}_{2} \mathrm{O}$. The twenty delta functions are retained, but the frequencies and weights are adjusted somewhat to fit the scattering data of Haywood ${ }^{(60)}$ and the double differential cross section data of Whittemore. (92) The fit is considerably better than can be obtained with the Honeck-Nelkin model.

Finally, just as in $\mathrm{H}_{2} \mathrm{O}$, the incoherent scattering can be described approximately in terms of a frequency spectrum $\rho(\beta)$ measured by experiment. While contributions due to coherent scattering, and the significant oxygen contribution, make a precise determination of $\rho(\beta)$ even more difficult than in $\mathrm{H}_{2} \mathrm{O}$, measured frequency spectra for $\mathrm{D}_{2} \mathrm{O}$ have been reported in the literature (see e.g., Page ${ }^{(61)}$ Haywood and Page, ${ }^{(68)}$ and Harling ${ }^{(93)}$ for recent 
measurements). The paper of Haywood and Page also shows the corrections applied to the data to account for multiple scattering and scattering by oxygen: the overall correction is quite significant.

d. Evaluation of Existing Kernels

As first observed by Honeck, the incoherent HoneckNelkin model predicts the total cross section for $\mathrm{E}>.01 \mathrm{eV}$, as well as diffusion and diffusion cooling coefficients, quite well. A series of experiments performed at General Atomic $(94,95,96)$ have subjected this model to more severe tests. Neutron spectra have been measured in $\mathrm{D}_{2} \mathrm{O}$ solutions of both $1 / v$ and resonance absorbers and the results compared to predictions based on the Honeck-Nelkin model. These experiments, which are summarized by McNeil, et al, (97) show that except for $\mathrm{E}<.01 \mathrm{eV}$ this model predicts infinite medium spectra very closely, while spectra measured at the surface of the system, where anisotropic effects are most pronounced, are in error by about $12 \%$. (As a contrast, predictions based on the Brown-St. John model are also shown, and exhibit considerably larger errors.) These results are in accord with the observations of Koppel and Young that coherent effects are significant only when the energy is low or when quantities sensitive to the angular dependence of the cross section are considered.

Both the MR model, in which the parameters are selected to fit the double differential cross section data, and the 
Egelstaff-Schofield model, in which the frequency spectrum is determined directly from the data itself, provide a better representation of the angular-dependent cross section than is possible with the Honeck-Nelkin model.(72)(93) Presumably these models would also predict space-dependent spectra more closely, but unfortunately no extensive calculations have yet been reported. A comparison of infinite medium spectra based on the Honeck-Nelkin model, and on Haywood's measured frequency spectrum, has been reported by General Atomic, ${ }^{(98)}$ and shows (unsurprisingly) a negligible difference for $\mathrm{E}>.01 \mathrm{eV}$. At lower energies the predicted spectra differ by about $6 \%$. It will be of considerable interest to compare the space-dependent spectra predicted by these two models.

Finally, it is of interest to ask how significant the above differences in cross sections and spectra are to the reactor designer who is more interested in quantities such as reactivity, conversion ratios, and temperature coefficients. A study of this question has been reported by Suich ${ }^{(99)}$ who compares calculations of these parameters based on the Honeck-Nelkin model with those based on the ideal gas and Brown-St.John model. While different boundatom models are not compared, the differences would probably be smaller than those between the Honeck-Nelkin and the gaslike models. Suich concludes that the Honeck-Nelkin model will produce errors of a few tenths of $1 \%$ in reactivity in 
$\mathrm{U}-\mathrm{D}_{2} \mathrm{O}$ and $\mathrm{Pu}-\mathrm{D}_{2} \mathrm{O}$ systems, and errors of $1-2 \%$ in conversion ratios and eta in $U-D_{2} O$ systems. Temperature coefficients may have errors as large as $10-15 \%$.

e. Recommendations for Future Work

Some extensions of the work reported by Suich would be of interest. For example, the calculation of eta, reported for $U-D_{2} \mathrm{O}$ systems, would be expected to be somewhat more sensitive to the scattering kernel in $\mathrm{Pu}-\mathrm{D}_{2} \mathrm{O}$ systems because of the epithermal resonance in $\mathrm{Pu}$. It would be of interest to determine the degree of sensitivity. In addition, if materials such as graphite or beryllium (perhaps reflectors) were present in a $\mathrm{D}_{2} \mathrm{O}$ system, the rapid variation of their cross sections near the Bragg cutoff would make their thermal average cross sections sensitive to the shape of the thermal flux, and thus to the scattering law of $\mathrm{D}_{2} \mathrm{O}$. The degree of this sensitivity should be determined.

If either of the above quantities is found to be sensitive to differences between bound-atom models, the use of a model more sophisticated than the Honeck-Nelkin model would be indicated.

Finally, we have noted that the deficiencies of the Honeck-Nelkin model, and indeed of any incoherent model, are most likely to be pronounced in cases when anisotropic scattering is important. Thus transport calculations should be carried out for the most compact type of $\mathrm{Pu}-\mathrm{D}_{2} \mathrm{O}$ 
lattices expected to be encountered in the near future to determine whether anisotropic scattering need be considered. (An estimate to the importance of the $P_{1}$ component to the scattering cross section might be obtained by comparing calculations based on the Honeck-Nelkin model using the $\mathrm{P}_{0}$ component alone with calculations based on the $\mathrm{P}_{0}$ and $\mathrm{P}_{1}$ components.) If the $P_{1}$ component is found to be significant, it will be necessary to determine whether a more sophisticated incoherent kernel, perhaps using the MR or an experimental frequency spectrum, is adequate, or whether a complete coherent kernel will be needed. The comparison of experimental space-dependent spectra with the predictions of various incoherent kernels should help to decide this question, and if such calculations are not reported in the near future they should certainly be carried out.

If more detailed theoretical models are indicated, several extensions should be possible:

a) The measured frequency spectrum of $\mathrm{D}_{2} \mathrm{O}$ might be supplemented by a simple diffusive model of the molecular translations to determine the spectrum in the region of small frequencies, which is not accessible to measurement.

b) The effects of the anisotropy of molecular vibrations might be considered in the same manner as in the KoppelYoung model for water.

c) The inter-molecular interference effects might be calculated more precisely by using the experimental 
pair correlation function rather than the hard sphere model used by Butler.

The above extensions would not involve any major theoretical problems; rather the primary problems are those of numerical analysis: how to calculate the cross section accurately without using a prohibitive amount of computer time. This could be a challenging problem area, requiring the development of sophisticated approximation methods for various ranges of energies.

\section{Macroscopic Reactor Calculations}

Thus far the review of the development of calculational methods has dealt mainly with methods used to calculate the properties of a unit cell of the reactor. The physics of the complete reactor are determined from the properties of the unit cell using one of two general methods, the homogeneous or the heterogeneous method.

\section{Homogeneous Methods}

In the homogeneous method the properties of the homogenized unit cell are generally used in a few-group diffusion theory calculation. Many diffusion theory codes have been developed. Basically, they are all similar in that they solve the diffusion theory equations using finite-difference methods. Some differences between the various codes are the number of energy groups, the number of spatial dimensions, the amount of spatial detail, the inclusion or exclusion of upscattering, and the number of groups for downscattering.

The following are some of the many available diffusion theory codes : 
One-dimensional codes: FOG (4 gps, AI) ${ }^{(32)}$, FAIM (18 gps, AI) ${ }^{(33)}$, HFN (20 gps, BNW) ${ }^{(34)}$;

Two-dimensional codes: ZADOC (2 gps, Winfrith) ${ }^{(35)}, 20-$ GRAND (6 gps, ORNL) ${ }^{(36)}$, GAMBLE (10 gps, GGA) ${ }^{(37)}$, PDQ (5 gps, Westinghouse) ${ }^{(38)}$, EXTERMINATOR ( $\sim 50 \mathrm{gps}$, ORNL) ${ }^{(39)}, 2 \mathrm{DB}$ ( $\sim 50 \mathrm{gps}$, $\mathrm{BNW}){ }^{(40)}$;

Three-dimensional codes: WHIRLAWAY (2 gp, ORNL) ${ }^{(41)}$, PERIGEE (2 gp, AECL) $^{(42)}$, VIRVEL (2 gp, ASEA-
Sweden)

An exact analysis of a reactor in three dimensions is in many cases prohibitively expensive, and of ten exceeds the capacities of existing computers. Synthesis methods have been developed which allow a fairly inexpensive analysis of the complex three-dimensional problems.

Kaplan (47) has written a report on the development of synthesis methods up to about 1965. A further review of synthesis techniques is given by Carter ${ }^{(1)}$ in a review published in 1968.

\section{Heterogeneous Methods}

In the heterogeneous method one considers each fuel assembly as a line sink and source of neutrons with parameters determined from cell calculations.

Because of the very heterogeneous nature of most $\mathrm{D}_{2} \mathrm{O}$ lattices and the fact that very mixed loadings can result from on-line, bidirectional refueling or other causes, the heterogeneous methods would appear to be a particularly natural approach to these $D_{2} O$ 
reactor designs. There has been considerable recent interest among certain groups, especially in Europe, in the development of heterogeneous source-sink methods. However, other groups seem to feel that since reactors have been built and can be designed without using heterogeneous methods, the need for heterogeneous methods is questionable, except for some special applications. This feeling was expressed in a summary of a panel discussion ${ }^{(45)}$ concerning heterogeneous methods at the Joint International Conference on the Physics Problems in Thermal Reactor Design, held in London, June 1967.

The Savannah River Laboratory has been the main U. S. proponent of heterogeneous methods, and is currently using the codes HERESY I ${ }^{(46)}$ and HERESY II ${ }^{(47)}$, which respectively employ two and up to ten energy groups. Although they are useful in their present form, these codes do suffer from a number of deficiencies, such as restrictions to effectively infinite lattices or reflectors, the assumption of zero diameter fuel assemblies, and the inability to consider moderation within fuel assemblies.

Another heterogeneous code, developed and being used at Chalk River, is the two-group MICRETE ${ }^{(48)}$ code.

Some of the heterogeneous methods developed and being used in Europe are as follows:

Recent Swedish work on heterogeneous codes has resulted in the code DIP ${ }^{(49)}$ (dipoles, two-dimensional), with the additional options MOP (only monopoles, two-dimensional) and MOPZ (three- 
dimensiona1). These codes differ from the older HETERO ${ }^{(50)}$ codes in that they assume a finite radius of fuel elements and control rods. They can accommodate ten energy groups.

Swiss work in collaboration with the Swedish group has led to improvements in the three-dimensional Source-Sink program sos. An arbitrary number of energy groups and azimuthal harmonics are included. A second heterogeneous code, BARCO ${ }^{(52)}$, treats partially inserted control rods in homogenized cores.

The French are using a three-dimensional heterogeneous code, ASTYANAX. (53) Fourier expansions with from ten to fifteen harmonics are used to represent axial distributions.

The British have developed a two-dimensional heterogeneous code PRESTO ${ }^{(54)}$ and have applied it to analyses of the Steam Generating Heavy Water Reactor. This code uses a finite fuel element radius and includes dipole components of the flux.

As a result of the extensive European work on heterogeneous methods, theoretical methods are in existence for removing the restrictions presently contained in the HERESY codes. However, these advanced techniques need to be imported and adapted to U. S. computing machines before they can be used here. 


\section{REACTOR DATA AND ANALYTICAL CORRELATIONS}

The adequacy of any calculational method, that is meant for calculation of reactor physics parameters, has to be tested by applying the method to a variety of reactor experiments. In order to do this, one needs to have available an extensive body of experimental data.

Reactor studies can be divided into categories, according to the complexity of the physical make-up of the lattice. In this section three categories are used, which in order of complexity are: 1) uniform lattices of rods, 2) uniform lattices of clusters, and 3) power reactors. We investigate the status of experimental data and the adequacy of calculational methods as they apply to these three categories, by reviewing some of the important recent experimental and analytical studies.

\section{A. Uniform Lattices of Rods}

It is important to be able to accurately predict the physics characteristics of simple uniform lattices of rods, because if the calculational methods cannot accurately predict the characteristics of simple systems, they are unlikely to be able to predict the characteristics of the more complex power reactors.

\section{Status of Experimental Studies}

A large amount of experimental information has been available for some time for natural uranium- $\mathrm{D}_{2} \mathrm{O}$ lattices. A compilation was made by Honeck and Crandall ${ }^{(4)}$ in 1964 of most of the data existing then.

A. B. Atomenergi of Sweden has recently conducted studies (exponential and critical) of single-rod lattices of $\mathrm{UO}_{2}$ (natural and slightly enriched), $\mathrm{UO}_{2}-2$ at\% $\mathrm{PuO}_{2}$, or natural 
$\mathrm{ThO}_{2}$. Both uniform and mixed lattices were studied. The measurements comprised studies of material bucklings, spectral indices, and conversion ratios as functions of fuel composition and lattice pitch.

At Saclay, France, substitution experiments ${ }^{(100)}$ have been carried out in a natural uranium metal lattice with U-Pu fuel rods containing $0.04 \%$ or $0.30 \%$ plutonium. Bucklings were measured as a function of lattice pitch.

A series of eight clean exponential experiments ${ }^{(101)}$ has recently been conducted by Brookhaven National Laboratory using $\mathrm{ThO}_{2}-3 \%{ }^{233} \mathrm{UO}_{2}$ fuel rods in $\mathrm{D}_{2} \mathrm{O}$. These measurements comprised studies of material bucklings, dysprosium thermal disadvantage factors, ratios of epi-cadmium to sub-cadmium captures in 232 Th, and ratios of fissions in ${ }^{232}$ Th to those in ${ }^{233} \mathrm{U}$. The Massachusetts Institute of Technology group has been engaged in the Heavy Water Lattice Project. They have accumulated an impressive amount of data ${ }^{(102)}$ on slightly enriched uranium metal lattices, as well as on oxide fuels. The quantities measured have included buckling, $\rho^{28}, \delta^{25}, \delta^{28}$, and the modified conversion ratio. A single element method has been investigated, which combines measurements on a single fuel element with a theory which relates the behavior of the lattice of such elements to the experimentally determined behavior of the single element. A moments method ${ }^{(103)}$ has been developed for the analysis of flux distributions in subcritical assemblies. The method can be applied successfully to very small lattices as well as to large exponential assemblies. 


\section{Status of Analytical Correlations}

Recent analytical correlations $(104,105)$, of natural uranium experiments, by Savannah River Laboratory and Combustion Engineering using the HAMMER ${ }^{(25)}$ code indicate excellent agreement. These studies show the largest discrepancy in $k_{\text {eff }}$ is about $1.5 \%$ and the average slightly less than $1 \%$.

Concerning the Swedish work, material bucklings calculated ${ }^{(30)}$ with the FLEF code (integral transport theory) are systematically low. There is also a clear trend with lattice pitch, the predicted reactivity getting progressively worse as the lattice pitch is decreased. The reactivity discrepancy is $1-2.5 \%$ for the uranium systems, and somewhat larger for the plutoniumenriched systems.

Calculations ${ }^{(106)}$ by Brookhaven National Laboratory of their thorium oxide-uranium oxide experiments yield values of $k_{\text {eff }}$ which are on the average about $1.2 \%$ too low, using the HAMMER ${ }^{(25)}$ code. The reasons for the discrepancies are not fully understood; however, the experiments may be suspect because of the high leakage. Calculated dysprosium thermal disadvantage factors are about $2 \%$ higher than the measurements; ratios of epi-cadmium to sub-cadmium captures in ${ }^{232}$ Th are generally in good agreement except for the most concentrated lattice; and calculated ratios of fissions in ${ }^{232}$ Th to those in $233_{U}$ are lower than measured values. Clean geometry-critical experiments with this fuel would be helpful in attempting to resolve the discrepancy that exists. Application of the HAMMER ${ }^{(25)}$ code to the recent Swedish experiments ${ }^{(30)}$ may also be helpful 
in resolving existing discrepancies.

Existing calculational methods are in general adequate for natural uranium-fueled lattices of single rods. For systems containing fuels other than natural uranium discrepancies do exist. More work needs to be done in the development of calculational methods before experiments in uniform lattices of rods become superfluous.

\section{B. Uniform Lattices of Clusters}

Uniform lattices of clusters represent the next higher order of complexity in reactor studies. The most important geometrical configuration for heavy water reactors is the lattice of clustered fuel elements. Therefore, the experiments in this category provide a more stringent and more realistic test of calculational methods than experiments with single rod lattices. Because of the large number of possible designs for a $\mathrm{D}_{2} \mathrm{O}$ reactor, the experiments with uniform lattices of clusters cover a wide range of fuels and coolants.

1. Status of Experimental Studies

Recent Projects. Quite a large number of experiments have been conducted recently with uniform lattices of clusters. Many of these experiments were performed in support of specific reactor projects. Some of these recent projects are the following:

- The Swedish work ${ }^{(107)}$ at Studsvik in support of the Marviken reactor using 31 -rod clusters of $1.2 \%$ enriched $\mathrm{UO}_{2}$ and 61 -rod clusters of $1.8 \%$ enriched $\mathrm{UO}_{2}$.

- Swedish work ${ }^{(108)}$ in support of the Agesta reactor using 19-rod clusters of natural $\mathrm{UO}_{2}$. 
- The experiments ${ }^{(109)}$ at Winfrith, England in support of the Steam Generating Heavy Water Reactor using 74-rod clusters of several types of fuel, e.g., $1.35 \%$ enriched $\mathrm{UO}_{2}, 0.91 \%$ enriched $\mathrm{UO}_{2}$ with $0.25 \% \mathrm{PuO}_{2}$, and $0.43 \%$ enriched $\mathrm{UO}_{2}$ with $0.8 \% \mathrm{PuO}_{2}$.

- Experiments ${ }^{(110)}$ at Saclay, France in support of the EL-4 reactor using 19 -rod clusters of $1.65 \%$ enriched $\mathrm{UO}_{2}$ and 18 -rod clusters of $1.37 \%$ enriched $\mathrm{UO}_{2}$.

- Experiments ${ }^{(111)}$ at CISE, Segrate, Italy in support of the CIRENE reactor using 7-tube clusters of natural uranium metal and 19-rod clusters of natural $\mathrm{UO}_{2}$.

- Euratom experiments ${ }^{(112)}$ in support of the Orgel project which include 1) experiments at Ispra, Italy with 19rod clusters of natural uranium metal, 2) experiments (113) at Chalk River in cooperation with AECL using 7-rod clusters of UC, and 3) experiments at Bologna, Italy, in cooperation with CNEN using 7-rod clusters of UC.

- Measurements ${ }^{(114)}$ with 28-rod clusters of natural uranium at Chalk River in support of the CANDU-BLW reactor. - Swiss studies ${ }^{(115)}$ with 19 - and 37-rod clusters of natural uranium.

Thorium has received considerable attention as an important fertile material. Thorium fuels have been used in experiments at several laboratories. Early measurements ${ }^{(116)}$ were conducted at Argonne National Laboratory using thorium oxide fuel containing $2 \%$ and $4 \%$ highly enriched $\mathrm{UO}_{2}$ (THUD fuel). More recent experiments using thorium fuel clusters are the following: Brookhaven 
National Laboratory has investigated ${ }^{(117)} 31$-rod clusters of $\mathrm{ThO}_{2}-3 \% \mathrm{U}^{233} \mathrm{O}_{2}$ fuel rods; Chalk River experiments ${ }^{(118)}$ using 19 -rod clusters of $\mathrm{ThO}_{2}$ containing $1.5 \%$ highly enriched $\mathrm{UO}_{2}$; Savannah River studies (119) with 85 -rod clusters of Thud fuel, and of fuel containing a thorium- ${ }^{235} \mathrm{U}$ ratio of 49.03 as part of the recently discontinued HWOCR project of the USAEC; and measurements ${ }^{(120)}$ at Studsvik, Sweden, in a joint National Committee for Nuclear Energy (CNEN)-Halden Project-A. B. Atomenergi Project using 7-rod clusters of $\mathrm{ThO}_{2}$ fuel containing $2 \% \mathrm{U}^{235} \mathrm{O}_{2}$.

Plutonium fuels have been studied at Battelle-Northwest under the USAEC Plutonium Utilization Program. These studies $(121,122,157)$ have utilized 19-rod clusters of Al-1.8 wt\% $\mathrm{Pu}$ and $\mathrm{UO}_{2}-2$ wt\% $\mathrm{PuO}_{2}$, and have been concerned with the recycle of plutonium in thermal reactors. The experiments have been conducted in support of the Plutonium Recycle Test Reactor. Methods evaluations conducted under the program can be helpful even to those who are not specifically interested in plutonium recycle since they can be helpful in determining the ability of various codes to handle plutonium. This is important to everyone working in the field for in equilibrium uranium cores $50 \%$ or more of the fissions can occur in plutonium that has been produced from ${ }^{238} \mathrm{U}$. A review of reactor physics data acquired from Pu-fueled experiments is given in Reference 157. Simulated burned-up uranium fuels, containing small amounts of plutonium, have been used in some studies. At Savannah River and at Chalk River 19- and 31-rod clusters have been studied $(123,124)$ 
which contain three different concentrations of plutonium, $0.259,0.294$, and $0.340 \mathrm{wt} \%$ plutonium.

At Winfrith, England, experiments ${ }^{(125)}$ in support of the Steam Generating Heavy Water Reactor project included fuels with two concentrations of plutonium, 0.25 and $0.80 \mathrm{wt} \%$ plutonium.

Scope of Experiments. In general, most of the cluster studies mentioned in this section have included measurements of buckling and cell-fine structure parameters. Some of the studies have used several of the common coolants, such as $\mathrm{D}_{2} \mathrm{O}, \mathrm{H}_{2} \mathrm{O}$, air, and various organics.

There has been a deficiency of experimental data concerning coefficients of reactivity, especially coolant temperature coefficients. Such information can, of course, be obtained from operating power reactors, but it would be desirable to have this information from critical experiments. Two specific categories of temperature coefficients that have suffered from a lack of data are 1) temperature coefficients of burned-up cores, and 2) temperature coefficients of $\mathrm{H}_{2} \mathrm{O}$-cooled heavy water reactors.

The Winfrith studies with SGHWR fuel have included measurements of the coolant temperature coefficient. An early Winfrith experiment ${ }^{(126)}$ attempted to simulate temperature-dependent effects by using mixtures of $\mathrm{H}_{2} \mathrm{O}$ and $\mathrm{D}_{2} \mathrm{O}$ to simulate reductions of coolant density. More recent experiments ${ }^{(127)}$ have been conducted in which a SGHWR cell has been pressurized and heated up to $270^{\circ} \mathrm{C}$.

The Savannah River Laboratory has been conducting temperature coefficient measurements using 31-rod clusters of simulated burned-up fuel. In these experiments they have used four different coolants to simulate boiling light water coolant. The 
Savannah River measurements will provide much-needed data on reactivity coefficients of burned-up cores. The range of these temperature coefficient measurements needs to be extended to other lattice pitches and other coolants.

Both the Savannah River and Winfrith temperature coefficient experiments have been conducted with $\mathrm{H}_{2} \mathrm{O}$ coolant. The $\mathrm{H}_{2} \mathrm{O}$ cooled, $\mathrm{D}_{2} \mathrm{O}$ moderated reactor concept is receiving considerable interest. In addition to the British SGHWR, the Canadian CANDU-BLW ${ }^{(128)}$ and the Italian CIRENE Reactor (129) represent this reactor concept. The prediction of temperature coefficients in these reactors is complicated by the fact that two very different moderators, $\mathrm{H}_{2} \mathrm{O}$ and $\mathrm{D}_{2} \mathrm{O}$, at different temperatures, have to be considered in the cell calculation. Measurements of temperature coefficients are thus very helpful for evaluating calculational methods, and should be extended to include other fuels and other lattice pitches.

\section{Status of Analytical Correlations}

All of the experimental studies of cluster lattices have been accompanied by calculational studies. Some calculational studies have been confined to the use of recipes, while other studies have included the use of more sophisticated calculational tools.

Recipes. Recent calculational studies using recipes include the following:

- The Swedish code REBUS ${ }^{(7)}$ (an improved version of the early BURNUP ${ }^{(6)}$ code) was applied ${ }^{(130)}$ to more than 250 experimental bucklings reported from six nations. The 
overall $k_{\infty}$ for all cases is $0.9990 \pm 0.0150$ (root mean square deviation) and $90 \%$ of the values fall between 0.98 and 1.02. Although the general agreement is good, calculated reactivities are too high for increasing enrichment, for increasing number of rods in a cluster, and for increasing moderator-to-fuel volume ratios;

- Canadian investigation ${ }^{(131)}$ covering a total of 41 natural uranium lattices was performed to determine the accuracy of four-factor, 2-group recipes. It was determined that calculated $k_{\text {eff }}$ values show systematic trends with pitch, type of fuel cluster, and with coolant;

- At Ispra, the code PLUTHARCo ${ }^{(9)}$ has been applied ${ }^{(112)}$ to about 50 natural uranium lattices. It was concluded that the buckling results agree reasonably well with experiments, but that $k_{\infty}$ values for 19-rod uranium metal clusters and for 7-rod clusters of uranium carbide are underestimated.

More Sophisticated Methods. Recent calculational studies using more sophisticated calculational tools include the following:

- At Ispra, EURATOM has applied ${ }^{(112)}$ the code PINOCCHIO ${ }^{(31)}$ to about 200 lattices. Three types of fuels were considered ( $\left.\mathrm{U}, \mathrm{UO}_{2}, \mathrm{UC}\right)$, in lattices covering moderator-to-fuel volume ratios between 5 and 61 . Included in the analysis were clusters of 4,7 , and 19 rods, with $\mathrm{D}_{2} \mathrm{O}, \mathrm{H}_{2} \mathrm{O}$, organic, or air coolant. In general the agreement between PINOCCHIO results and the experiments is good. About $60 \%$ 
of all calculated values of $k_{\text {eff }}$ lay within $\pm 0.5 \%$ of the experimental $k_{\text {eff }}$, and less than $10 \%$ of the cases were in disagreement by more than $\pm 1 \%$. A systematic underestimation of $k_{\text {eff }}$ and $k_{\infty}$ was observed for 19-rod uranium metal clusters. It is felt that the main cause of errors in PINOCCHIO lies in the cylindrical homogenization of the cluster for the thermal cell calculation. Work is in progress at Ispra to allow the exact geometry of the cluster to be included in the thermal (THERMOS) calculations.

- At Winfrith, both the design method METHUSELAH ${ }^{(132)}$ and the more sophisticated method WIMS ${ }^{(29)}$ have been applied $(109,125,127)$ to several lattice experiments conducted in support of the SGHWR. The reactivity predictions of METHUSELAH are slightly better than those of WIMS, in which the ring-smearing option was used for the clusters. However, even with WIMS the worst case is only $1 \%$ lower than experiment. With mixed $\mathrm{PuO}_{2}-\mathrm{UO}_{2}$ fuels, eigenvalues calculated with Methuselah decrease with increasing ${ }^{239} \mathrm{Pu}$ content, while WIMS produces the opposite trend. The change in void coefficient with increasing plutonium content is predicted well by METHUSELAH, but it is recognized that there must be compensating errors which offset the incorrect prediction of plutonium/uranium fission ratios. In both uranium and plutonium fuels, METHUSELAH over-estimates the thermal flux shape (peaking) across a fuel cluster. The ring-to-ring distribution of fissions (thermal and fast) and of resonance events are predicted better by WIMS 
than by METHUSELAH. The WIMS code has been applied also to some Canadian ZED lattices. In only one case of 12 reported in Reference 132 does the calculated eigenvalue differ from experiment by more than 1 percent. An observation regarding uranium-238 resonance absorption has been made by the Winfrith group, on the basis of this and other studies using the WIMS code. They suggest that "... there appears to be strong evidence ... that the uranium-238 capture is overestimated in conditions where there is substantial selfshielding, and the discrepancy is thought to be due to data rather than method of calculation." (132) This suggestion has generated further investigation, for if, in fact, the accepted ${ }^{238} \mathrm{U}$ resonance integral is too large, this would have an effect on all calculations pertaining to uranium reactors. However, no convincing experimental cross section data have been obtained to substantiate this claim.

- At the Savannah River Laboratory the HAMMER ${ }^{(25)}$ code has been used in an analysis ${ }^{(119)}$ of ${ }^{235} \mathrm{UO}_{2}-\mathrm{ThO}_{2} 85$-rod-cluster experiments performed as part of the recently discontinued HWOCR project of the USAEC. Calculated and measured bucklings agreed to within $\pm 0.25 \mathrm{~m}^{-2}$, which corresponds to \pm 0.0075 in $k_{\infty}$. Intracell activation profiles were predicted adequately in most cases; spectral indices in coolants were overestimated by the HAMMER calculations; and the measured resonance capture in ${ }^{232}$ Th was 5 to $20 \%$ higher than that calculated. The one-dimensional HAMMER calculation was considered to be adequate for calculations of a survey 
nature.

The HAMMER code has also been applied ${ }^{(123)}$ at SRL to a series of experiments with $\mathrm{PuO}_{2} / \mathrm{UO}_{2}$ clusters containing three different concentrations of $\mathrm{PuO}_{2}$. No systematic differences between calculation and experiment due to type of coolant or fuel were observed. Agreement in general was good, but significant discrepancies were observed in the spectral index and resonance capture calculations. These discrepancies were tentatively attributed primarily to the use of a one-dimensional ring model for the highly heterogeneous clusters.

- At Combustion Engineering, a version* of the HAMMER ${ }^{(25)}$ code has been applied to analyze $e^{(105)}$ 1) a large number of Canadian ZED-2 experiments with clusters of $\mathrm{UO}_{2}, \mathrm{UC}$, and $\mathrm{U}$ metal, and 2) some SRL experiments with $\mathrm{PuO}_{2}-\mathrm{UO}_{2}$ clusters.

Calculated eigenvalues for $\mathrm{D}_{2} \mathrm{O}$ and air-cooled clusters are dependent on lattice pitch, whereas they are not so for organic-cooled clusters. The trend with lattice pitch varies from about $3 \%$ lower than experiment to $1.2 \%$ higher than experiment. Calculated fast fission and conversion ratios differ from measured values by amounts that are dependent on lattice pitch, coolant, and the number of rods in the cluster. In the case of $\mathrm{PuO}_{2}-\mathrm{UO}_{2}$ lattices, calculated eigenvalues are low by 2 to $3 \%$ and calculated values of $\rho^{28}$ are high by 3 to $10 \%$.

The discrepancies in $\rho^{28}$ and the dependence of eigenvalue on lattice pitch indicate that the resonance treatment *Early Brookhaven National Laboratory version. 
of HAMMER may be inadequate. The dependence of eigenvalue on number of rods per cluster indicates that the onedimensional model of cluster may be inadequate.

- At Battelle-Northwest the calculational scheme THERMOS ${ }^{(18)}$ $\mathrm{HRG}^{(28)}-\mathrm{HFN}{ }^{(34)}$ has been applied to analyze some plutoniumfueled experiments. For a two-zoned core ${ }^{(133)}$ of natural $\mathrm{UO}_{2}$ and $\mathrm{Al}-1.8 \mathrm{w} / \mathrm{o} \mathrm{Pu}$ the calculated $\mathrm{k}_{\text {eff }}$ is about $1 \%$ high; and for a lattice ${ }^{(121 \mathrm{~b})}$ of $\mathrm{Al}-1.8 \mathrm{w} / \mathrm{O} \mathrm{Pu}$ clusters only the calculated $k_{\text {eff }}$ is about $5 \%$ high; however, the validity of one-dimensional diffusion theory (HFN) is questionable in the latter case because the loading contained only seven 19rod clusters.

At the present time a detailed analysis (134) is underway of experiments conducted in the PRCF ${ }^{(122)}$ in support of a Batch Core loading ${ }^{(135)}$ of plutonium in the PRTR using 19rod clusters of $\mathrm{UO}_{2}-2 \mathrm{w} / \circ \mathrm{PuO}_{2}$. The purpose of the analysis is to determine the limitations of various calculational methods in their application to plutonium-fueled thermal reactor systems. The codes being used are: HAMMER (27) and HTH ${ }^{(136)}$ (HRG-THERMOS-HFN). In addition to the codes HFN and FLOG, which are contained, respectively, in HTH and HAMMER, the EXTERMINATOR code (two-dimensional) is being used for reactor calculations.

A large and diverse amount of experimental information exists for uniform lattices of clusters in $D_{2} 0$ moderator. Because much of the data has been gathered in support of specific reactor projects, most experimental programs have not systematically covered a wide 
range of variables, e.g., lattice pitch or fuel enrichment. Therefore, there are gaps in the body of experimental data that need to be filled if a systematic study of calculational methods is to be made over a wide range of variables. Some of these gaps are: temperature and void coefficients of lattices of simulated burned-up fuel; temperature and void coefficients of $\mathrm{H}_{2} \mathrm{O}$-cooled lattices of all fuels of interest; experiments in general with plutonium-containing fuels simulating highly burned-up fuel; experiments in general with actual burned-up fuel; experiments with thorium fuels.

Discrepancies exist between experiment and calculation and between various calculational methods. Comparison of calculational results is hampered by the use of different sets of basic nuclear data by different laboratories. Systematic calculations over a wide range of lattices need to be done with several calculational methods using consistent basic data.

C. POWER REACTORS

1. Status of Experimental Work

The ultimate goal of reactor physics studies is to be able to predict accurately the behavior of actual power reactors. Thus, the ultimate test of calculational methods is provided by physics data obtained from operating power reactors. Unfortunately, there is only a relatively small amount of such data available. One reason for the deficiency of physics data from operating $\mathrm{D}_{2} \mathrm{O}$ power reactors is that there are relatively few $\mathrm{D}_{2} \mathrm{O}$ power reactors in operation. A second reason is that most power reactors have not been designed to conveniently yield physics data. Furthermore, a problem arises because the reactor designer and the reactor 
operator have different goals. The reactor operator cannot afford to devote as much time to physics experiments as the designer would like, and much of the physics information that has been obtained during operation has not been systematically organized and reported.

Physics experiments at the time of reactor startup supply data with which to verify design calculations. These experiments, though somewhat more complex, are often not very different from zero power critical experiments with uniform lattices of clusters. Physics experiments at various stages of burnup would supply data with which to verify burnup calculations. These measurements, along with measurements of operating coefficients of the power reactor, are obtainable only from a power reactor.

Recent reports of power reactor physics studies have appeared in the following compilations:

- Proceedings of an IAEA Panel of Fuel Burnup Prediction in Thermal Reactors, Vienna, April 1967. (137)

- IAEA Symposium on Heavy Water Power Reactors, Vienna, September 1967. (138)

- British Nuclear Energy Society Conference on Steam Generating and Other Heavy Water Reactors, London, May 1968. (139)

- European Nuclear Energy Association Seminar on Physics Measurements in Operating Power Reactors, Rome, May 1966. (140)

The first of the above compilations contains excellent reviews of the state-of-the-technology, and sets forth some useful 
conclusions and recommendations. Parts of these reviews, conclusions and recommendations are contained in this report.

Experiments in the $\mathrm{D}_{2} \mathrm{O}$-cooled, $\mathrm{UO}_{2}(1.5 \%$ and $2 \%$ enriched) fueled Carolinas Virginia Tube Reactor (CVTR) have been reported by Westinghouse. This program has included measurements, at various stages of burnup, of temperature coefficients, differential moderator worth, control rod worths, and reactivity depletion rate. Measurements were also made of xenon transients, power coefficient, decay heat, and direct deposition of fission energy in the moderator system.

An experimental program ${ }^{(142)}$ of burnup physics has been conducted with the second fuel charge of the Halden Heavy Boiling-Water $\underline{\text { Reactor }}$ in Norway. This fuel charge consisted of 7-rod clusters of $1.5 \%$ enriched $\mathrm{UO}_{2}$. A series of measurements including critical size determination, temperature reactivity coefficient, power void coefficient, cell parameter studies, and dynamic characteristics were conducted at zero burnup. Before final shutdown, measurements were made in the burned core of: critical size, temperature reactivity coefficient, and void power coefficient. The core had an estimated average burnup of $6200 \mathrm{MWd} / \mathrm{tU}$. Spectral indices were measured in coolant channels at various stages of burnup. Determinations of isotopic compositions of burned-up fuel are being carried out in cooperation with $A B$ Atomenergi of Sweden. Both destructive (mass spectrographic) and nondestructive (gamma scanning) analyses are being done. Pile oscillator techniques, using samples of burned fuel are being used in cooperation with $A B$ Atomenergi to deduce changes in cross sections with exposure. The third Halden 
core has been a mixture of various fuel assemblies, and has been used mainly to test these various fuels.

Physics experiments have been conducted ${ }^{(143)}$ in the Agesta Reactor, which is a pressure vessel reactor fueled with 19-rod clusters of natural $\mathrm{UO}_{2} \cdot$ An extensive series of experiments was performed at zero burnup, and measurements were made at several stages of burnup of excess reactivity, control rod patterns, temperature coefficient, power distribution, and activation of spectrum-sensitive foils. Determinations of isotopic compositions of burned-up fuel are being made using both destructive and nondestructive techniques.

A large-scale burnup experiment ${ }^{(135)}$ (the Batch Core Experiment) is underway in the Plutonium Recycle Test Reactor (PRTR). The basic fuel loading, which consists of 55 19-rod clusters of $\mathrm{UO}_{2}-2 \mathrm{w} / \mathrm{\circ} \mathrm{PuO}_{2}$, will remain essentially unperturbed to the end of core reactivity lifetime, thus providing a unique set of data for use in checking methods of calculating reactivity lifetimes of reactor cores. This feature is noteworthy because results of previous experiments (e.g., in the Halden and Agesta reactors) suffered because of non-uniformities in loading patterns and frequent movement of fuel. In the current PRTR experiment the central zone of 55 elements is surrounded by a buffer zone of similar fuel elements which separates the core from the test fuel elements on the periphery. No control rods or shim rods are present to perturb the core because the reactor is controlled by varying the moderator height. Reactivity coefficients, the boron concentration for the just critical situation, and the isotopic 
concentration as a function of exposure are being measured. As of January 1969 an average exposure of 5300 MWd/MTM has been achieved for the 55-element core. Earlier PRTR operation has provided useful data ${ }^{(144)}$ on changes in isotopic composition of burned-up clusters of Al-Pu alloys. Both destructive and nondestructive techniques are used to obtain data on isotopic compositions. In addition to the isotopic data, effective cross section ratios have been deduced from the fuels and used in correlation $(145,146)$ of calculational methods. Determination of effective cross section ratios allow separate evaluation of cell calculation methods and of burnup calculation techniques. In addition, the effective cross sections are a more severe test of the methods than isotopic concentrations or reactivity measurements.

The Canadian heavy-water-cooled NPD reactor ${ }^{(147)}$ has been operating with a natural uranium fuel charge near equilibrium burnup for a bi-directional fueling cycle. It is a wellcontrolled critical experiment with irradiated fuel, in which the irradiation history of each fuel bundle is known. Nevertheless, complications arise in the analysis of this loading, because of the presence of many types of experimental fuel bundles. Chemical analyses have been performed to determine plutonium/uranium ratios of burned-up fuel, and mass spectrometric analyses have been made to determine isotopic compositions.

Startup experiments from other reactors, such as the British SGHWR ${ }^{(148)}$, the French EL4 ${ }^{(110)}$, the German MZFR ${ }^{(149)}$, and the Canadian Douglas Point Candu reactor $(150,151)$, provide some additional physics information. These reactors are also sources 
for future information regarding burnup problems.

An accurate knowledge of the power distribution in the reactor is essential for accurate prediction of burnup. For typical, highly heterogeneous loadings involving mixed fuels, empty channels, etc., the precision of the knowledge of the power distribution has often been very poor. In an attempt to improve the knowledge of power distributions, emphasis has been recently placed on extensive in-core instrumentation. Future studies in the Halden reactor will have extensive in-core instrumentation, as does the new Swedish Marviken reactor.

\section{Status of Analytical Correlations}

Methods used to calculate the physics behavior of $\mathrm{D}_{2} \mathrm{O}$ power reactors are basically the same as those used to calculate the behavior of zero-power critical lattices of clusters. There are additional complications, such as the presence of control rods and other perturbations, and the effects of thermal hydraulics on the physics behavior of the reactor.

A further problem in the calculation of power reactors is that of determining the burnup, i.e., the change in fuel isotopic composition as a function of irradiation. This is of utmost importance from a fuel-management and economic viewpoint. It is also important from the viewpoint of reactor behavior because many important reactor physics quantities change as a function of burnup.

Calculational methods used for predicting fuel burnup can be classified, as were the calculational methods mentioned in Section II, as 1) cell methods (or point burnup methods) or 2) macroscopic 
methods. Cell methods are used to evaluate burnup within individual fuel elements and macroscopic methods are used to perform over-all reactor calculations using the results of cell burnup calculations. The cell methods are useful in themselves for predicting changes in reaction rates and fuel composition for a cell which is typical of a given portion of the reactor core. The cell codes include both recipe-type codes, e.g., REBUS ${ }^{(7)}$ (Sweden) and MELEAGER ${ }^{(152)}$ (BNW), and more sophisticated codes that attempt to take into account the geometry of the unit cell, e.g., PINOCCHIO ${ }^{(31)}$ (EURATOM), METHUSELAH ${ }^{(132)}$ (Winfrith), and FLEF ${ }^{(30)}$ (Sweden). The ultimate goal, however, of burnup calculations is to be able to predict fuel burnup over the whole reactor.

The physics behavior of a power reactor presents a complex three-dimensional problem. The analysis is complicated by perturbations such as control rods, and by the effects of thermal-hydraulics. The latter effects are especially important in cases where the coolant is boiling water, because boiling introduces a non-uniform distribution of voids throughout the reactor. If the void coefficient of reactivity is appreciable, a non-uniform void distribution has an important influence on the behavior and burnup of the reactor. Thermal hydraulic effects are generally taken into account by coupling reactor physics codes to thermal-hydraulic codes.

The widespread use of detailed three-dimensional calculations, such as the British JOSHUA ${ }^{(153)}$ scheme, the French TRICYCLES ${ }^{(154)}$ scheme, or the Westinghouse TNT ${ }^{(155)}$ or PDQ-7 $(38)$ schemes, is limited by the very long computing times required. And in many practical cases the detail required for an accurate three-dimensional 
calculation exceeds the capacity of existing computing machines.

In some cases, for example, when the reactor loading contains fairly uniform zones of fuel, a two-dimensional calculation such as the British METHSELAH-ZADOC ${ }^{(156)}$ or AIMAZ ${ }^{(156)}$, the French POUSSE-

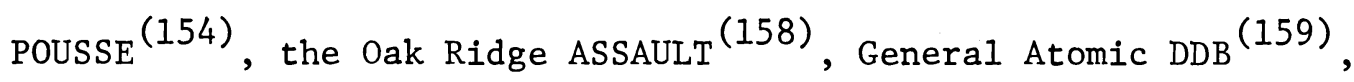
Westinghouse TURBO ${ }^{(160)}$, or the Swedish MABUS ${ }^{(161)}$ scheme is adequate; and if the loading consists of annular zones, a one-dimensional calculation; e.g., the Westinghouse CANDLE ${ }^{(162)}$, the Atomics International SIZZLE ${ }^{(163)}$, Battelle-Northwest ZODIAC-G ${ }^{(164)}$, or the Combustion Engineering version of HAMMER ${ }^{(165)}$ may be adequate. Synthesis techniques $(1,44)$ can be used in some cases to obtain a fairly inexpensive analysis of the complex three-dimensional problems.

An excellent review of current methods used for burnup calculations is presented in the Proceedings of an IAEA panel on Fuel Burnup in Thermal Reactors ${ }^{(137)}$, held in Vienna, April 1967. Papers were presented from England, Canada, Czechslovakia, France, the United States, Belgium, Japan, Sweden, Norway, and the USSR. A review of European American Committee on Reactor Physics activities in burnup physics was also presented. The general opinion of this panel was that the status of cell burnup codes is quite good, and that the main problem in burnup calculations is in the macroscopic calculation of the spatial flux and power distributions.

Some conclusions and recommendations from the 1967 IAEA Panel, which indicate the current state-of-the-technology of physics calculations for power reactors, are: 
- "The degree of detail required in the mathematical models, the speed and capacity of our computing devices, and the nature of our mathematical methods are still incommensurate. It is believed that our theory and data are adequate, but the computations required for practical, precise prediction are still very lengthy."

There is a need to

- "Develop reliable procedures for testing the precision and convergence of alternate mathematical techniques;

- "Improve the speed and stability of convergence of methods used to predict large, loosely-coupled cores;

- "Achieve some standards of characterization for heterogeneous codes;

- "Develop improved general methods for dealing with fuel and absorber management problems;

- "Develop improved methods for dealing with operational problems."

It was recommended

- "That standard reactor configurations, including some for which the representation of details is important, be recommended as calibration standards, with which the existing large variety of computing codes may be compared."

- "Need for more and better instrumentation to obtain precise, detailed data on operating power reactors" was stressed, as well as the need for publication of such data. 
IV. SUMMARY AND CONCLUSIONS

We have reviewed the status of heavy water reactor physics studies and, on the basis of this review, have indicated areas where further studies would be useful. Some of these areas are discussed below.

In the area of basic data, there is a continuing need to evaluate new measurements of cross sections and to update cross section libraries; there is a need for extensive measurements of the scattering law for $D_{2} O$ at high temperatures; and there is a need for systematic comparisons of various scattering kernels and slowing down theories--especially as to their effect on important reactor physics parameters such as reactivity, reactivity coefficients and power distributions.

Existing calculational methods are in general adequate for natural uranium-fueled lattices of single rods. For systems containing fuels other than natural uranium discrepancies do exist. More work needs to be done in the development of calculational methods before experiments in uniform lattices of rods become superfluous.

A large and diverse amount of experimental information exists for uniform lattices of clusters in $\mathrm{D}_{2} \mathrm{O}$ moderator. Because much of the data has been gathered in support of specific reactor projects, most experimental programs have not systematically covered a wide range of variables, e.g., lattice pitch or fuel enrichment. Therefore, there are gaps in the body of experimental data that need to be filled if a systematic study of calculational methods is to be made over a wide range of variables. Some of these gaps are: temperature and void coefficients of lattices of simulated burned-up fuel; temperature and void coefficients of $\mathrm{H}_{2} \mathrm{O}$-cooled lattices of all fuels of interest; experiments in general with plutonium-containing fuels simulating highly 
burned-up fuel; experiments in general with actual burned-up fuel; experiments with thorium fuels.

Discrepancies exist between experiment and calculation and between various calculational methods. Comparison of calculational results is hampered by the use of different sets of basic nuclear data by different laboratories. Systematic calculations over a wide range of lattices need to be done with several calculational methods using consistent basic data.

The ultimate goal of reactor physics studies is to be able to predict accurately the behavior of actual power reactors. Thus, the ultimate test of calculational methods is provided by physics data obtained from operating power reactors. There are many calculational methods available, but unfortunately, there is only a relatively small amount of experimental data available. There is a need for more and better instrumentation to obtain precise, detailed, physics data from operating power reactors. There is also a need for such detailed data to be published so that the many existing calculational methods can be meaningfully evaluated. It is felt that the biggest problem in burnup calculations is in the macroscopic calculation of the complex spatial flux and power distributions. There is a need for the development of improved general methods for dealing with fuel management problems and operational problems. 


\section{REFERENCES}

1. N. E. Carter. Review of Methods used for Computing the Kinetic Behavior of Large Power Reactors, BNWL-738, Pacific Northwest Laboratory, Richland, Washington, January 1968.

2. "Heavy Water Lattices: Second Panel Report, "IAEA Technical Report, Series No. 20, Vienna, 1963.

3. J. L. Cranda11, et a1. "Lattice Studies and Critical Experiments in $\mathrm{D}_{2} \mathrm{O}-$ Moderated Systems," Third International Conference on Peaceful Uses of Atomic Energy, P/ 268, Vol. 3, p. 126, United Nations 1965.

4. H. C. Honeck and J. L. Cranda11. The Physics of Heavy Water Lattices, BNL-8253, Brookhaven National Laboratory, June 1964.

5. C. H. Westcott, et a1. "Effective Cross Sections and Cd Ratios for the Neutron Spectra of Thermal Reactors," Proc. 2nd UN Conf. Atomic Energy, 16, 70 (1958).

6. B. Pershagen. "Heavy Water Lattice Calculations in Sweden," Heavy Water Lattices: Second Panel Report, Technical Report Series No. 20, p. 257 IAEA, Vienna, 1965 .

7. P. E. Ahlstrom and P. E. Blomberg. "Methods for Fuel Burn-up Prediction used in Sweden," Fuel Burn-up Predictions in Therma1 Reactors, IAEA, Vienna, 1968.

8. I. H. Gibson. The Physics of LATREP, AECL-2548, Atomic Energy of Canada Limited, 1966.

9. W. de Haan and R. Meelhuysen. PLUTHARCO: A Plutonium, Uranium, Thorium Assemb1y Reactivity Code, Physica1 Concepts, Comparisons with Experiments and Code Description. EUR-3141, European Atomic Energy Comm., Ispra, August 25, 1966.

10. F. E. Driggers. Heavy Water Lattices: Second Pane1 Report, pp. 551-572, IAEA, Vienna, 1963.

11. W. L. Brooks, et al. Present Status of Calculation and Experiment for D20-Moderated Natura1 Uranium Lattices, UNC-5062, 1963.

12. R. G. St. Paul and S. A. Raje. NDC: A Fortran Program for Unit Cell Nuclear Design Calculations for Rod-Clustered Pressure Tube Lattices, CVNA-146, 1962 .

13. C. R. Richey. IDIOT: A Lattice Parameter Code for the IBM-709, HW-63411 General Electric Company, Richland, Washington, 1960. 
14. J. Jedruch, et a1. Physics Properties of Clustered $\mathrm{UO}_{2}-\mathrm{D}_{2} \mathrm{O}$ Lattices at Various Lattice Pitches, CVNA-133, Westinghouse Electric Corporation, October 1962 .

15. H. Boh1, Jr., E. M. Gelbard, G. H. Ryan. Fast Neutron Spectrum Code for the IBM-704, USAEC Report WAPD-TM-72, Westinghouse Corp., July, 1957.

16. H. Boh1, Jr., et a1. PIMG - A One-Dimensional Multigroup $P$ Code for the IBM-704, WAPD-TM-135. Westinghouse Corp., (Bettis) Pittsburgh, Pa. July 1959.

17. R. A. Dannels and S. M. Hendley. REPLICA, Monte Carlo Code to Calculate Resonance Capture in a Lattice of 19-Rod Hexagona1 Clusters, CVNA-130, 1962 .

18. H. C. Honcek. THERMOS, A Thermalization Transport Theory Code for Reactor Lattice Calculations. BNL-5826, Brookhaven National Laboratory, September 1961.

19. G. G. Bilodeau, et al. PDQ - An IBM-704 Code to Solve the Two-Dimensional Few-Group Neutron Diffusion Equation, WAPD-TM-70.

20. B. I. Spinrad and R. W. Meier. "Remarks on the Physics of Heavy Water Lattices," Heavy Water Lattices: Second Pane1 Report, p. 602-603, IAEA Technica1 Report Series No. 20, Vienna, 1963.

21. D. Hicks. "Few-Group Nuclear Design Methods for Heavy Water Reactors," Heavy Water Lattices: Second Panel Report, p. 371-415, IAEA Technical Report Series No. 20, Vienna, 1963.

22. D. C. Leslie and M. J. Terry. "A Preliminary Description of THULE," Heavy Water Lattices - Second Panel Report, p. 417-443, IAEA Technical Report Series No. 20, Vienna, 1963.

23. B. Carlson, C. Lee, and J. Worlton. The DSN and TDC Neutron Transport Codes. LAMS-2346, 1960.

24. D. J. McGoff. FORM-A Fourier Transform Fast Spectrum Code for the IBM-709, NAA-SR-Memo-5766, Atomics International, September 1960.

25. J. E. Suich and H. C. Honeck. The HAMMER System, Heterogeneous Analysis by Multigroup Methods of Exponentials and Reactors, DP-1064, E. I. du Pont de Nemours and Co., Savannah River Laboratory, 1967.

26. G. F. Kuncir. A Program for the Calculation of Resonance Integrals, GA-2525, Genera1 Atomic, August 28, 1961.

27. H. C. Honeck, private communication 1968.

28. J. L. Carter, Jr. "Computer Code Abstracts, Computer Code-HRG," Reactor Physics Department Technical Activities Quarter1y Report - July, August, September, 1966, BNWL-340, Pacific Northwest Laboratory, October 15, 1966. 
29. J. R. Askew, F. J. Fayers, and D. B. Kemshe11. "A General Description of the Lattice Code WIMS," J. Brit. Nucl. Energy Soc., p. 564, Oct., 1966.

30. C. E. Wikdah1, et a1. "Studies of Single-Rod Lattices of $\mathrm{UO}_{2}$ (Natural and Enriched), $\mathrm{PuO}_{2}$ or $\mathrm{ThO}_{2}$ in Heavy Water," BNES Int. Conf. On Physics Problems in Thermal Reactor Design, p. 103, London June 1967.

31. R. Bonalumi. "Neutron First Collision Probabilities in Reactor Physics," Energia Nucleare, $8,326,1961$.

32. H. P. Flatt. The FOG One-Dimensional Neutron Diffusion Codes, NAA-SR-6104, North Am. Aviation, Inc. 1961.

33. D. C. Baller. The FAIM Code - A Multigroup, One-Dimensional Diffusion Equation Code, NAA-SR-7137 (1961)

34. J. R. Lilley, Computer Code HFN-Multigroup, Multiregion Diffusion Theory in One Space Dimension, HW-71545, General Electric Company, Richland, Washington, 1961.

35. F. R. A1len. ZADOC - A Two-Group, Two-Dimensional Fuel Management Program for IBM 7090 or STRETCH," AEEW-R425, 1965 and M. J. Dickson, Developments of the ZADOC Code, (to be published).

36. M. L. Tobias and T. B. Fowler. The Twenty Grand Program for the Numerical Solution of Few-Group Neutron Diffusion Equations in Two Dimensions, ORNL-3200, February 1962.

37. J. P. Dorsey. GAMBLE-4, A Program for the Solution of the Multigroup Neutron Diffusion Equations in Two Dimensions with Arbitrary Group Scattering, for the IBM 7044 Fortran IV System, GA-6540, July 1, 1965.

38. W. R. Cadwe1l, et al. The PDQ -5 and PDQ -6 Programs for the Solution of the Two-Dimensional Neutron Diffusion-Depletion Problem, WAPD-TM-477, Westinghouse Electric Corp., 1965, and PDQ-7 Reference Manual. WAPD-TM-678 (1967).

39. T. B. Fowler, et a1., EXTERMINATOR-2: A Fortran IV Code for Solving Multigroup Neutron Diffusion Equations in Two Dimensions. ORNL-4078, Oak Ridge National Laboratory, April 1967.

40. W. W. Little and R. W. Hardie. 2DB, A Two-Dimensional Diffusion Burnup Code for Fast Reactor Analysis. BNWL-640, January 1968, and 2DB Users Manua1Revision 1, February 1969.

41. T. B. Fowler and M. L. Tobias. WHIRLAWAY-A Three-Dimensiona1, Two-Group Neutron Diffusion Code for the IBM 7090 Computer. Oak Ridge National Laboratory, Oak Ridge, Tennessee. 
42. A. P. 01son. PERIGEE Computer Codes for Reactor Simulation in Three Dimensions, Using 1 or 2 Neutron Velocity Groups, CRRP-1184, Atomic Energy of Canada Limited, February 1964. and Appendix 1, September 1964.

43. P. E. Ahlstrom and P. E. Blomberg. "Methods for Fuel Burnup Prediction used in Sweden," Fuel Burn-up Predictions in Thermal Reactors, IAEA Panel, Vienna, 1968.

44. S. Kaplan. "Synthesis Methods in Reactor Analysis," Advances in Nuclear Science and Technology, edited by P. R. Greebler and E. J. Henley. Academic Press, New York, 1966. pp. 233-266.

45. BNES International Conference on the Physics Problems in Thermal Reactor Design, p. 235, London, 1967.

46. C. N. Klahr, et a1., Heterogeneous Reactor Calculation Methods," Quarterly Progress Report No. 6, July 1, 1960 to September 30, 1960. (USAEC Report NYO-2678 (1960).

47. C. N. Klahr, et al. "Heterogeneous Reactor Calculation Methods," Quarterly Progress Report No. 7, October 1, 1960 to December 31, 1960, USAEC Report NYO-2679 (1960).

48. J. D. Stewart, J. M. Kennedy, S. J. Cowley. MICRETE, a G-20 Program for Calculation of Finite Lattices by the Microscopic-Discrete-Theory, AECL-2547, Atomic Energy of Canada Limited, 1966.

49. A Jonsson, G. Naslund, $A B$ Atomenergi Report (in preparation) also see Ref. 40.

50. G. Naslund. "HETERO: Description of Program for IBM-7044," AB Atomenergie Reports, TPM-RFN-176 (1964), TPM-RFN-187 (1965), TPM-RFN-188 (1965), TPM-RFN-193 (1965), TPM-RFN-206 (1965) and TPM-RFN-249 (1966), (in Swedish).

51. T. Overbach, G. Burnand, H. Soodak. "The Heterogeneous Method and its Application," Third Geneva Conference, P.690, United Nations, 1964.

52. R. W. Meier. "Reactor Physics Activities in Switzerland," Reactor Physics in OECD Countries, October 1965-June 1966, EACRP-L-63, March 1967.

53. M. Chabrillac, et a1. "Experimental Flux Distributions in EL4 and Comparison with Three-Dimensional Heterogeneous Calculations," BNES Int. Conf. on Physics Problems in Thermal Reactor Design, p. 168, London, 1967.

54. F. R. Allen, "PRESTO-I - A Programm for Multigroup Source-Sink Calculations in Pressure Tube Reactor Lattices," AEEW, (to be published). 
55. H. C. Honeck. ENDF/B - Specifications for an Evaluated Nuclear Data File for Reactor Applications, BNL-50066 (T-467), May 1966.

56. G. Goertzel and E. Greuling. "An Approximate Method for Treating Neutron Slowing Down," Nucl. Sci. \& Eng., 7, 69-72 (1960).

57. G. D. Joanou and J. S. Dudek. GAM-I: A Consistent P1 Multigroup Code for the Calculation of Fast Neutron Spectra and Multigroup Constants, GA-1850 (June 1961).

58. F. T. Adler, G. W. Hinman, and L. W. Nordheim. "The Quantitative Evaluation of Resonance Integrals," Proc. of Sec. U.N. Conf. on Peaceful Uses of Atomic Energy, 16, 155-171 (1958).

59. P. A. Egelstaff, "The Theory of the Thermal-Neutron Scattering Law," Proc. of the Symp. on Inelastic Scattering of Neutrons in Solids and Liquids, Vienna, pp. 25-37. IAEA, 1960 and P. A. Egelstaff and P. Schofield. "On the Evaluation of the Thermal Neutron Scattering Law," Nuc. Sci. and Eng. Vo1. 12, pp. 260-270, 1962.

60. B. C. Haywood. A Compilation of the Scattering Law for Heavy Water at $22^{\circ} \mathrm{C}$ and $150^{\circ} \mathrm{C}, \overline{A E R E-R 4582 . ~ U n i t e d ~ K i n g d o m ~ A t o m i c ~ E n e r g y ~ R e s e a r c h ~}$ Establishment, 1964 .

61. D. I. Page, Scattering Law S (alpha, beta)-Values for Heavy Water at $540^{\circ} \mathrm{K}$, AERE- R-5408. United Kingdom Atomic Energy Authority Research Group, 1967.

62. 0. K. Harling. Compilation of Doubly Differential Cross Sections and the Scattering Law for $\mathrm{H}_{2} \mathrm{O}$ and $\mathrm{D}_{2} \mathrm{O}$ at $299^{\circ} \mathrm{K}$ and for $\mathrm{H}_{2} \mathrm{O}$ at $268^{\circ} \mathrm{K}$, BNWL-436, Pacific Northwest Laboratory, Richland, Washington, 1967.

63. W. L. Whittemore. Differential Neutron Thermalization, Annual Summary Report, GA-7439, General Atomic, Division of General Dynamics, 1967.

64. W. Glaser. "A Review of Scattering Law Studies for Moderators," IAEA Conf. on Neutron Thermalization and Reactor Spectrum, Ann Arbor-USA, Ju1y 1967 SM $62 / 1$.

65. H. L. McMurry, G. J. Russel1 and R. M. Brugger. "Slow Neutron Scattering by Water," Nuc. Sci and Eng., 25, 248 (1966).

66. K. E. Larsson and V. Dahlborg. "A Study of the Diffusive Atomic Motions in Glycerol and of the Vibratory Motions in Glycerol and Light and Heavy Water by Cold Neutron Scattering," Proc. of Symposium on Inelastic Scattering of Neutrons in Solids and Liquids, Vol. 1, p. 317, IAEA, Vienna (1963).

67. E. L. Slaggie. "Multiple Scattering in Slow-Neutron Double Differential Measurements, Nuc. Sci. and Eng., 30, 199 (1967). 
68. B. C. Haywood and D. I. Page. "The Scattering Laws for Heavy Water at $540^{\circ} \mathrm{K}$ and Light Water at $550^{\circ} \mathrm{K}$, IAEA Conference on Neutron Thermalization and Reactor Spectra, Ann Arbor, USA, July 1967 SM 96/19

69. 0. K. Harling. Slow Neutron Inelastic Scattering and the Dynamics of Heavy Water, to be published. Pacific Northwest Laboratory, Richland, Washington.

70. H. L. McMurry, G. J. Russell and R. M. Brugger. "Slow-Neutron Scattering by Water," Nuc1. Sci. and Eng., 25, p. 248 (1966).

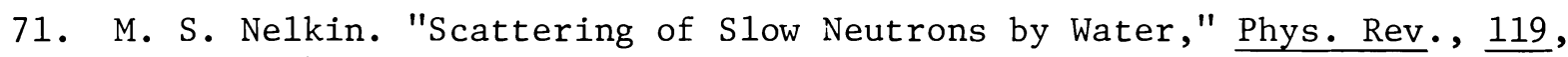
741 (1960).

72. H. L. McMurry. Model for Calculating the Slow Neutron Scattering by Liquid $\mathrm{D}_{2} \mathrm{O}$," USAEC Report, IN-1020, August, 1966.

73. P. A. Egelstaff. "The Theory of the Thermal-Neutron Scattering Law," Proc. of Symposium on Inelastic Scattering of Neutrons in Solids and Liquids, pp. 25-37, IAEA 1960.

74. R.C.F. McLatchie. Theoretical Physics Division, A.E.R.E. Harwell, England, unpublished data, 1962.

75. D. Butler. "The Scattering of Slow Neutrons by Heavy Water, I: Intramolecular Scattering," Proc. Phys. Soc. London, 81, p 276 and 294 (1963).

76. J. U. Koppel and J. A. Young. "The Role of Interference Scattering in Neutron Thermalization by Heavy Water," Nukleonik, $\underline{7}, 408$ (1965).

77. L. Van Hove. "Correlations in Space and Time and Born Approximation Scattering in Systems of Interacting Particles," Phys. Rev., 95, 249 (1954).

78. E. P. Wigner, and J. E. Wilkins, Jr. Effect of the Temperature of the Moderator on the Velocity Distribution of Neutrons with Numerical Calculations for $\mathrm{H}$ as Moderator, USAEC Report AECD-2275, Oak Ridge National Laboratory, 1944.

79. H. D. Brown and D. S. St. John, Neutron Energy Spectrum in $\mathrm{D}_{2} \mathrm{O}$, USAEC Report DP-33, Savannah River Laboratory, 1954 (Dec1. 1955).

80. A. C. Zemach and R. J. Glauber. "Dynamics of Neutron Scattering by Molecules, Phys. Rev., 101, 118 (1956).

81. J. U. Koppe1 and J. A. Young. "Neutron Scattering by Water, Taking into Account the Anisotropy of the Molecular Vibrations," Nucl. Sci. and Eng., 19, 412 (1964). 
82. G. H. Vineyard. "Scattering of slow neutrons by a Liquid," Phys. Rev., 110, 999 (1958)

83. E. L. Slaggie. "Multiple Scattering in Slow-Neutron Double-Differential Measurement," Nucl. Sci. and Eng., 30, 199 (1957).

84. B. C. Haywood. "The Spectral Density of Hydrogen in Water," J. Nuc. Energy, 21,249 (1967).

85. 0. K. Harling. "Neutron Inelastic Scattering Study of Light Water and Ice," To be published in the June 15, 1969 issue of J. of Chem. Phys.

86. H. C. Honeck. "A Review of Methods for Computing Thermal Neutron Spectra," IAEA Symposium on Neutron Thermalization and Reactor Spectra, Ann Arbor, Michigan, August 1967.

87. H. C. Honeck. "An Incoherent Thermal Scattering Model for Heavy Water," Trans. Am. Nuc1. Soc., 5, No. 1, 47 (1962).

88. G. Pleczek. "The Scattering of Neutrons by Systems of Heavy Nuclei," Phys. Rev., 86, 377 (1952).

89. B. N. Brockhouse. "Structural Dynamics of Water by Neutron Spectrometry," Nuovo Cim (Supp1.), 9, 45 (1958).

90. T. Springer. "Study Group on Utilization of Reactors in Organized Research," International Atomic Energy Agency Athens, Greece; September 9-13, 1963, CONF-426.

91. J. R. Beyster, H. Antunez, W. Brouwer, et al. "Integral Neutron Thermalization," Annual Summary Report for Oct. 1, 1964-September 30, 1965, USAEC Report, GA-6824, (1965).

92. W. L. Whittenmore. "Differential Neutron Thermalization," Annual Summary Report, October 1, 1965-September 30, 1966, USAEC Report, GA-7439 (1967)

93. 0. K. Harling. "Slow-Neutron Inelastic Scattering and the Dynamics of Heavy Water," Nuc. Sci. and Eng., 33, 41-50 (1968).

94. J. R. Beyster, J. R. Brown, J. U Koppel, et al. "Integral Neutron Thermalization," Annual Summary Report, October 1, 1962-September 30, 1963, USAEC Report, GA-4659 (1964).

95. J. R. Beyster, J. R. Brown, N. Corngold, et a1., "Integral Neutron Thermalization," Annual Summary Report, October 1, 1963-September 30, 1964, USAEC Report, GA-5798 (1964).

96. J. R. Beyster, H. Antunez, W. Brouwer, et al. "Integral Neutron Thermalization," Annual Summary Report, October 1, 1964-September 30, 1965, USAEC Report GA-6824(1965). 
97. J. M. McNeil, et al. "Neutron Spectra in $\mathrm{H}_{2} \mathrm{O}, \mathrm{D}_{2} \mathrm{O}, \mathrm{BeO}$, and $\mathrm{CH}_{2}$ " IAEA Symposium on Pulsed Neutron Research, Karlsruhe, Germany, May, 1965.

98. J. R. Beyster, H. Antunez, G. Borgonovi, et al. "Integral Neutron Thermalization," Annual Summary Report, October 1, 1965-September 30, 1966, GA-7480 (1966).

99. J. E. Suich. "The Sensitivity of $\mathrm{D}_{2} \mathrm{O}$ Moderated Reactor Parameters to the Thermal Neutron Scattering Law," Conference on Neutron Cross Section Technology, Washington, D.C., March, 1966.

100. R. Nandet. "Interpretation D'experiences Critiques Portant Sur Des Combustibles Uranium-Plutonium," Proc. of Panel on Fuel Burnup Predictions in Thermal Reactors," p. 109, IAEA, Vienna, 1968.

101. H. H. Windsor and W. J. Tunney. "Reactor Physics Parameters of $233 \mathrm{UO}_{2}-$ $\mathrm{ThO}_{2}$ Lattices in $\mathrm{D}_{2} \mathrm{O}$," Trans. Am. Nucl. Soc., 10, 595 (1967).

102. T. J. Thompson, I. Kaplan, and M. T. Driscoll. "Heavy Water Lattice Project Final Report," MIT-2344-12, MITNE-86, Sept. 30, 1967 and other reports referenced in the Final Report.

103. H. S. Cheng, I. Kaplan, T. J. Thompson, M. J. Driscoll. "Use of A Moments Method for the Analysis of Flux Distributions in Subcritical Assemblies," MIT-2344-11, MITNE-84 (1968).

104. J. L. Cranda11, Private Communication, Savannah River Laboratory, 1967.

105. R. S. Harding, Private Communication, Combustion Engineering, 1967.

106. Bal Raj Sehgal. "Brookhaven ${ }^{233} \mathrm{U}_{-\mathrm{ThO}_{2}}$ Thermal Lattice Experiments," paper presented at the Tokyo meeting (October 1967) of the EACRP.

107. 0. Norinder. "Physics Design Aspects of the Marviken Reactor," IAEA Symposium on Heavy Water Power Reactors, paper SM-99/.39, Vienna, 1967.

108. R. Persson, et al. Buckling Measurements up to $250^{\circ} \mathrm{C}$ on Lattices of Agesta Clusters and on $\mathrm{D}_{2} \mathrm{O}$ Alone in the Pressurized Exponential Assembly TZ, AE-254, $\mathrm{AB}$ Atomenergie, 1966.

109. A. J. Briggs, et a1. "Further Reactor Physics Studies for SGHWRs-Part 1, Uniform Cluster Lattices Containing $\mathrm{UO}_{2}$ or $\mathrm{PuO}_{2} / \mathrm{UO}_{2}$ Fuel," J. Brit. Nucl. Energy Soc., Vo. 7, p. 61, January 1968.

110. M. Chabrillac, et a1. "Experimental Flux Distributions in EL-4 and Comparison with Three-Dimensional Heterogeneous Calculations," BNES Int. Conf. on the Physics Problems in Thermal Reactor Design, p. 168, London, 1967; and Y. Girald and J. Geffroy. "The Physical Aspect of Testing and Bringing the EL.4 into Power Operation," IAEA Symposium on Heavy Water Power Reactors, Vienna, 1967. Paper SM-99/51. 
111. F. Accinni, et al. "Evaluation of Lattice Parameters for a Heavy Water Moderated, Natural Uranium Fuelled Power Reactor," BNES Int. Conf. on the Physics Problems in Thermal Reactor Design, London, 1967, p. 172 .

112. L. Amyot, et a1. "Heavy Water Lattice Analyses at Ispra," Brit. Nuc. Energy Soc. Int. Conf. on the Physics Problems in Thermal Reactor Design, London, June 1967, p. 117.

113. R. E. Kay and R. E. Green. Lattice Measurements with 7-rod Clusters of Natural Uranium Carbide in Heavy Water Moderator, Part 1: Neutron Density Fine Structures in a Lattice Ce11, AECL-2650, Atomic Energy of Canada, Ltd., November 1966.

114. R. E. Kay and C. J. Tanner. CANDU-BLW Experiments in ZED-2, Part I: Refuelling Experiment, AECL-2667, January 1967; R. E. Kay, Part II: Booster Rod Experiments, AECL-2689, March 1967; R. F. Green, et a1. Part III: Buckling and Loss of Coolant Experiments, AECL-2691, May 1967.

115. W. Heer, et al. "Measurement of Material Buckling and Diffusion Coefficient in Heavy Water Moderated Lattices Containing Natural UO 2 Fuel Clusters," Brit. Nuc. Energy Soc. Int. Conf. on the Physics Problems in Thermal Reactor Design, London, 1967, p. 111.

116. W. C. Redman, et al. Critical Experiments with Urania-Thoria Fuel in Heavy Water, ANL-6378, Argonne National Laboratory, December 1961.

117. G. A. Price, et al. Organic-Cooled, Heavy-Water-Moderated, U-233 Fueled Lattice Experiments, BNL-50012 (T-434), Brookhaven National Laboratory, August 1966.

118. A Okazaki and S. A. Durrani. Lattice Measurements with 19-Element Rods of $\mathrm{ThO}_{2}-\mathrm{U}^{235} \mathrm{O}_{2}$ in Heavy-Water Moderator, AECL-2778, Atomic Energy of Canada, Ltd, October 1967 .

119. D. J. Pellarin, et al. Zero Power Experiments with 235U-Enriched Thoria and Thorium Metal Lattices for the HWDCR, DP-1125, Savannah River Laboratory, November 1967.

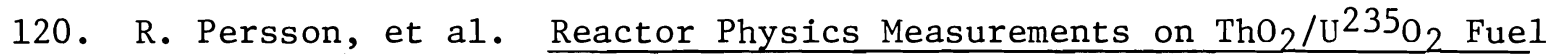
Assemblies in RO, AE-FFR-113, AB Atomenergi, Sweden, Nov. 1967.

121. R. A. Bennett and L. C. Schmid. Approach to Critical and Calibration Experiments in the Plutonium Recycle Critical Facility, HW-80206, Hanford Works, July 1964, and U. P. Jenquin, unpublished, Battelle-Northwest and EACRP Compilation of $\mathrm{D}_{2} 0$ Lattice Data, EACRP-L-42.

122. J. W. Kutcher, et al. "Critical Experiments with $\mathrm{PuO}_{2}-\mathrm{UO}_{2}$ Fuel and $\mathrm{D}_{2} \mathrm{O}$ Moderator," Trans. Am. Nuc1. Soc., 9, 448 (1967). 
123. N. P. Baumann, et a1. Lattice Experiments with Simulated Burned-up Fuel for $\mathrm{D}_{2} 0$ Power Reactors, DP-1122, Savannah River Laboratory, Feb. 1968, and Trans. Am. Nucl. Soc., 11, 254 (1968).

124. P. M. French and R. Solheim. "Experimental Bucklings of Simulated BurnedUp Natural Uranium Clusters in heavy Water," Trans. Am. Nucl. Soc., 11, 251, (1968).

125. G. H. Kinchin. "Physics of Plutonium Recycling in Thermal Reactors," Plutonium as a Reactor Fuel, Proc. of IAEA Symp. Brussels, March 1967, p.29.

126. C. G. Campbe11, et al. "Reactor Physics Studies for Steam Generating Heavy Water Reactors," Third Geneva Conf., United Nations, 1964, vo1. 3, P.174.

127. A. J. Briggs, et al. "Further Reactor Physics Studies for Steam Generating Heavy Water Reactors. Part 3: Coolant Temperature Effects in $\mathrm{UO}_{2}$ and $\mathrm{PuO}_{2} /$ $\mathrm{UO}_{2}$ Fuels," J. Brit. Nucl. Energy Soc., vol 7, p. 353, October, 1968.

128. G. A. Pon. "CANDU-BLW-250," Symposium on Heavy Water Power Reactors, IAEA, Vienna, September 1967, paper No. SM-99/32.

129. S. Villani. "The CIRENE Reactor Concept," Brit. Nuc. Ener. Soc., Conf. on Steam Generating and Other Power Reactors, London, May 1968, paper No. 15.

130. P. E. Ahlstrom, et al. "REBUS-HETERO-A Scheme for Reactor Physics and Burnup Calculations--Comparison with Experiments and Application to the Agesta Reactor," Brit. Nuc. Energy Soc. Int. Conf. on the Physics Problems in Thermal Reactor Design, London, 1967, p. 193.

131. A. Odazaki, B. M. Townes, and S. A. Durrani. "Chalk River Studies of $\mathrm{D}_{2} \mathrm{O}$ Moderated Natural Uranium and 235U-Thorium Lattices," BNES Int. Conf. on the Physics Problems in Thermal Reactor Design, London, 1967, p. 95.

132. F. J. Fayers and G. H. Kinchin. "Uranium and Plutonium Fuelled Lattices with Graphite and Water Moderation--A Comparison of Experiment and Theory," BNES Int. Conf, London 1967, paper No. 1.

133. V. O. Uotinen. A Poison-Free Loading of $\mathrm{UO}_{2}$ and $\mathrm{Pu}-\mathrm{Al}$ in the PRCF with $\mathrm{D}_{2} \mathrm{O}$ Moderator, BNWL-372, Pacific Northwest Laboratory, Richland, Washington, May 1967.

134. M. A. Mannan and D. L. Prezbindowski. "Theoretical Correlation of the PRTR Batch Core Experiment," Plutonium Utilization Program Technical Activities Quarterly Report, March, April, May 1969, BNWL report to be published, Pacific Northwest Laboratory, Richland, Washington.

135. J. R. Worden, W. L. Purcell and L. C. Schmid. Physics Experiment High Power Density Core of the PRTR, BNWL-221, and J. W. Kutcher and R. I. Smith, "PRTR Batch Core Experiment," Plutonium Utilization Program Technical Activities Quarterly Report, December 1967, January, February 1968, BNWL-739, Pacific Northwest Laboratory, Richland, Washington, April, 1968. 
136. D. R. Skeen, W. L. Purcell. Unpublished Data, Pacific Northwest Lab.

137. "Fuel Burn-Up Predictions in Thermal Reactors," Proc. of an IAEA Panel, Vienna, STI/PUB/172, 1968.

138. IAEA Symposium on Heavy Water Power Reactors, Vienna, Sept. 1967.

139. BNES Conference on Steam Generating and Other Heavy Water Reactors, London, May 1968.

140. Europ. Nuc. Energy Agency Seminar on Physics Measurements in Operating Power Reactors, Rome, May 1966.

141. R. J. Nath and T. F. Wyke. CVTR Core I Nuclear Operations Follow Summary, CVNA-280, July 1966.

142. J. E. Lunde. "Review of Burnup Physics Work with the HALDEN Heavy BoilingWater Reactor," Fuel Burn-Up Predictions in Thermal Reactors, STI/PUB/172, IAEA, Vienna, 1968.

143. G. Apelquist, et al. Physics Experiments at the Agesta Power Station, AE-244, AB Atomenergi, Sweden, September 1966.

144. W. A. Reardon and D. E. Christensen. "Atom Ratios and Effective Cross Section Ratios in Highly Depleted Plutonium-Aluminum Alloy Fuel," Nucl. Sci. and Eng., 30, 222-232 (1967).

145. R. P. Matsen. "A Technique for the Determination of Ratios of Effective Cross Sections from Reactor Fuel Burnup Data," Nucl. Sci. and Eng., 32, 267 (1968).

146. L. C. Schmid, et a1. "Experimental and Theoretical Methods used for Burnup Analysis at Battelle-Northwest," Trans - BNES Int. Conf. on Physics Problems in Thermal Reactor Design, London, England, June 1967, p. 241.

147. A. G. Ward. "Fuel Burnup and Reactivity Changes," Fuel Burnup Predictions in Thermal Reactors, Proc. of IAEA Pane1, STI/PUB/172, IAEA, Vienna, 1968.

148. D. Smith, et al. "Commissioning and Operating Experience with the Winfrith SGHWR," BNES Conf. on Steam Generating and other Heavy Water Reactors, London, May 1968.

149. E. Behrens, et al. "The Zero-Energy Experiment for the Multi-Purpose Reactor (MZFR)," Siemens Rev., 33:179-183, Siemens-Schuckert Research Center, Erlangen, Germany, March 1966.

150. A. A. Pasanen. "Predictions and Measurements of Physics Characteristics in the Douglas Point HWR, : Trans Am. Nucl. Soc., 11, 353, (1968). 
151. G. Brenciaglia. "Douglas Point Physics Measurements," BNES Int. Conf. on Physics Problems in Thermal Reactor Design, London, 1967, p. 201.

152. J. R. Triplett and G. J. Busselman. MELEAGER-A Burnup Code for Fuel Cycle Analysis, HW-68100, Hanford Works, March 1961.

153. F. R. Allen and D. A. Newmarch. "Core Representation in SGHW Reactors," BNES Int. Conf. on Physics Problems in Therma1 Reactor Design, London, 1967, p. 139 .

154. R. Naudet. "Fuel Management Studies for EL4," BNES Int. Conf. on the Physics Problems in Thermal Reactor Design, London 1967, p. 320. Also, EAES Meeting on Calc. Methods, Karlsruhe, 1966.

155. C. A. Flanagan, et a1. TNTO2-A Three-Dimensional Neutron Flux Synthesis and Depletion Calculation Computer Program, WAPD-TM-468 (1964.

156. D. Hicks, et a1. "Nuclear Design of SGHWRs," BNES Conf. on Steam Generating and other Heavy Water Reactors, London, May 1968, paper 4. (see also Ref. 39).

157. L. C. Schmid, et al. Reactor Physics Data for the Utilization of Plutonium in Thermal Power Reactors, BNWL-801, Pacific Northwest Laboratory, May 1968.

158. D. R. Vondy, et al. Reactor Depletion Code ASSAULT (Two-Dimensiona1, MultiNeutron Group Diffusion) ORNL-TM-1302, Oak Ridge National Lab., March 1966.

159. C. Cyl-Champlin, et a1. DDB - A Two-Dimensional Reactor Diffusion Code with Criticality Search and Burnout Options, GAMD-2797, General Atomic, March 1962.

160. S. M. Hendley and R. A. Mangan. TURBO - A Two-Dimensional Few-Group Depletion Code for the IBM-7090, WCAP-6059, Westinghouse Electric Corp., March 1964.

161. Palsson and B. Almgren. "MABUS, A Program for the Calculation of Macrascopic Burnup by use of Two-Group Diffusion Theory," AB Atomenergi Report RFR-532, 1966.

162. 0. J. Marlowe, et a1. Nuclear Reactor Depletion Programs for the Philco2000 Computer, WAPD-TM- 221 , Westinghouse Electric Corporation, January 1961.

163. D. P. Satkins and H. P. Flatt. "SIZZLE:NAA Program Description," Atomics International Internal Memorandum, February 1961.

164. D. D. Matsumoto and R. H. Holeman, "ZODIAC-G," Plutonium Utilization Program Technical Activities Quarterly Report, December 1967, January, February 1968, BNWL-739, Pacific Northwest Laboratory, April 1968.

165. R. S. Harding, personal communication, Combustion Engineering, 1967. 


\section{DISTRIBUTION}

No. of

Copies

OFFSITE
AEC Chicago Patent Group

G. H. Lee

AEC Division of Technical Information Extension

AEC Division of Reactor Development and Technology

A. J. Pressesky, Chief Analysis and Evaluation Branch

E. E. Kinter, Chief Core Design Branch

W. A. Williams, Chief Desalting Branch

J. W. Crawford, Asst. Dir. Engineering Standards

E. E. Kinter, Chief Fuel Fabrication Branch

J. M. Simmons, Chief Fuels and Materials Branch

A. N. Tardiff, Chief (2) Heavy Water Reactors Branch

R. W. Bean, Chief Instruments and Control Branch

J. A. Lieberman, Asst. Dir. Nuclear Safety

M. A. Rosen, Asst. Dir. Plant Engineering

D. E. Pollock, Asst. Dir. Program Analysis

A. Giambusso, Asst. Dir. Project Management

E. A. Kinter, Asst. Dir. Reactor Engineering

W. H. Hannum, Chief Reactor Physics Branch

E. E. Sinclair, Asst. Dir. Reactor Technology

N. Grossman, Chief Special Technology Branch

E. E. Erb', Acting Chief Water Projects Branch 
No. of

Copies

3

AEC Library, Washington

Division of Naval Reactors

A. Radkowsky

Division of Technical Information, MS149

W. E. Kee, Technology Utiliz. Off.

Office of General Counsel

R. A. Anderson, Asst. Gen. Counse1, Patents

1

1

1

1

1

6

AEC RDT Senior Site Representative

OROO, P.0. BOX X

Oak Ridge, Tennessee 37830

D. F. Cope

AEC RDT Site Representative

P. 0. Box 2108

Idaho Falls, Idaho 83401

K. A. Trickett

AEC RDT Site Representative

P.0. Box 500

Windsor, Connecticut 06095

G. U. Merckel

AEC RDT Site Office

P.0. Box 591

Canoga Park, California 91305

Robert L. Morgan, Senior Site Rep., AI

AEC Savannah River Operations Office

R. Thorne

Argonne National Laboratory

Reactor Physics Constants Center (4)

R. Avery

P. Gast

Atomic Energy of Canada Limited

M. Duret

C. Miller

A. Pasanen 


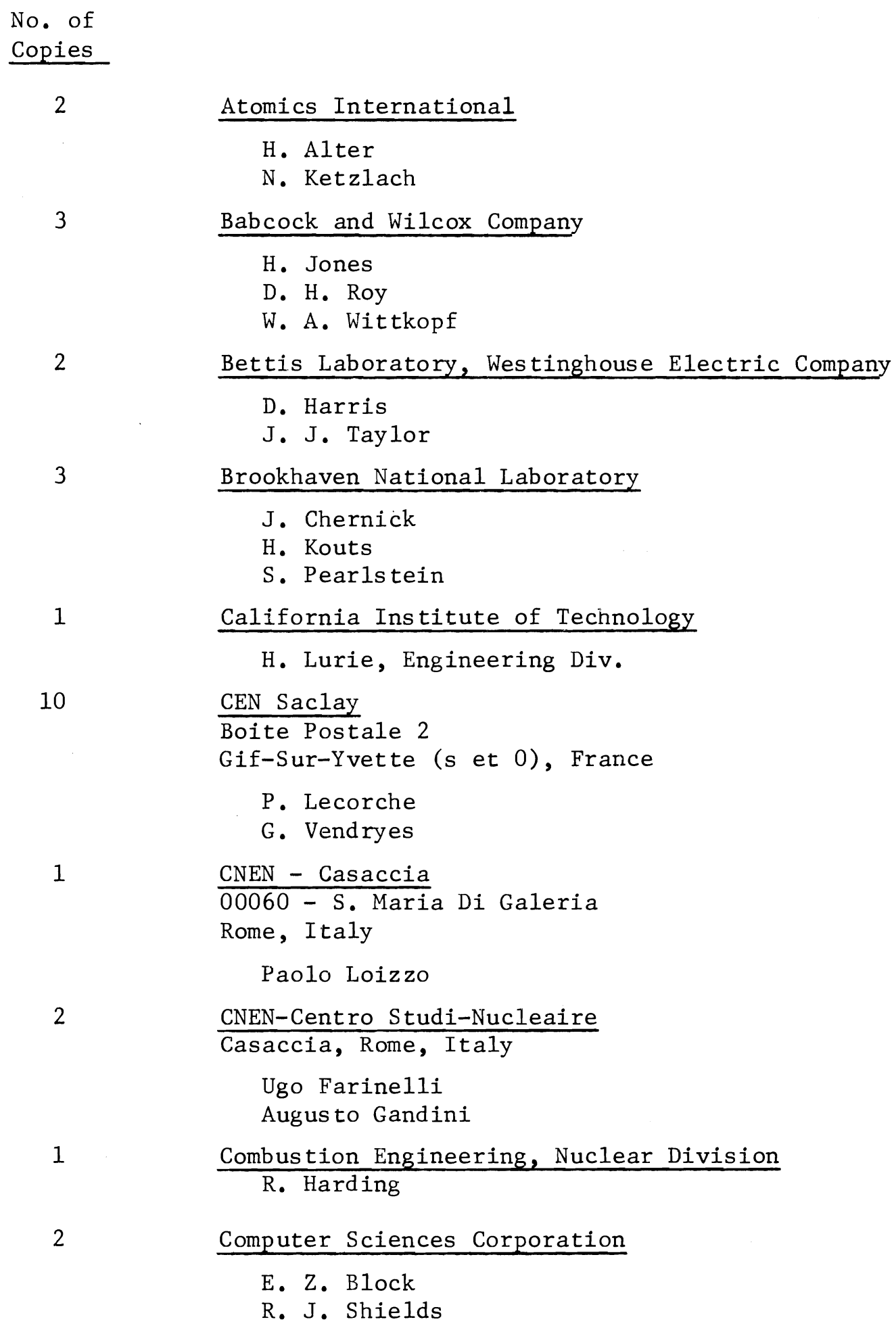


No. of

Copies

2

2

2

6

10

1

3
Cornel1 University, Ithaca, N. Y.

R. T. Cuykenda11, Eng. Physics

M. Nelkin

Assoc. C.E.N. Belgo Nucleaire

35 Rue Des Colonies, Belgium

H. Bairiot

L. Bindler

Duke University

Durham, N. C.

H. W. Newson, Physics Dept.

W. J. Seeley, School of Eng.

E. I. du Pont de Nemours \& Co., Inc.

Savannah River Laboratory

H. K. Clark

J. L. Crandall

G. Dessauer

E. J. Henne11y

H. Honeck

J. Suich

EURATOM

53, Rue Billiard

Brussels 4, Belgium

A. de Stordeur

FFR - AB Atomenergi

Studsvik, Pa NYKOPING

Sweden

Evelyn Sokolowski

General Atomic

J. M. Neill

L. W. Nordheim

H. B. Stewart

G. D. Trimble

General Electric Company

Knolls Atomic Power Laboratory

R. Ehrlich

C. Lubitz

K. W. Seeman 
No. of Copies

3

1

1

2

1

1

1

1

1

1

General Electric Company

San Jose

D. L. Fischer

P. Greebler

S. Levy

General Electric Company

$\mathrm{R}$ and $\mathrm{D}$ Center

Schenectady, N. Y.

W. R. Kanne

General Electric Company

Nucleonics Laboratory

H. W. Alter

Idaho Nuclear Inc.

R. G. Fluharty

E. Fast

Istanbul Technical University

Giimiis, suyer, Istanbul, Turkey

Director, Nuclear Energy Institute

Japan Atomic Energy Research Institute (JAERI)

Tokai-mura, Naka-gun, Ibarakiken, Japan

Hjime Sakata

Kansas State University

Manhattan, Kansas

W. R. Kime1, Nuclear Eng.

Kernforschungszentrum Karlsruhe

7500 Karls ruhe, Germany

Professor W. Haefele

Los Alamos Scientific Laboratory

G. E. Hansen

Manhattan College

Riverdale, New York, New York

Brother Gabriel Kane

Massachusetts Inst. of Technology

Prof. Irving Kaplan

D. D. Lanning

T. J. Thomps on 
No. of

Copies

1

1

1

2

1

1

1

1

1

1

North American Aviation Science Center

E. R. Cohen

North Carolina State College

R. L. Murray

Nuclear Materials and Equipment Corp.

Apollo, Pennsylvania

Kar1 Puech1

Oak Ridge National Laboratory

F. C. Maienochien

A. M. Perry

Pakistan Institute of Nuclear Science \& Technology

P.0. Nilore, Rawalpindi, Pakistan

M. A. Mannan

Penn. State College

W. F. Witzig

Phillips Petroleum Company

Idaho Falls, Idaho

W. B. Lewis

Power Reactor and Nuclear Fuel Development Corp.

9-13, 1-chome, Akasaka

Minato-ku, Tokyo, Japan

Setsuo Kobayashi

Purdue University

P. N. Powers, Nucl. Eng. Dept.

Rensselaer Polytechnic Institute

E. R. Gaerttner 
No. of

Copies

1

2

1

1

1

1

1

1

1

1
Union Carbide Corporation (ORNL)

E. B. Johnson

United Kingdom Atomic Energy Agency

Atomic Weapons Research Establishment

Aldermaston, Berkshire, UK

R. C. Lane (1)

Authority Health and Safety Branch, Safeguards Division, Risley,

Warrington, UK

J. H. Chalmers

United Kingdom Atomic Energy Authority

General Reactor Physics Division

Winfrith, England

C. G. Campbel1

United Nuclear Corporation

White Plains, N. Y.

G. Sofer

$\frac{\text { University of Arizona }}{\text { Tucson, Arizona }}$

Monte V. Davis, Nucl. Eng. Dept.

University of Florida

Gainesville, Florida

R. E. Uhrig, Nuc1. Eng.

University of Illinois

Urbana, Illinois

Frederick Seitz, Physics Dept.

University of Minnesota

Minneapolis, Minnesota

H. S. Isben, Chem. Eng. Dept.

University of Nevada

Reno, Nevada

T. V. Frazier, Physics Dept.

University of Notre Dame

Notre Dame, Indiana

E. W. Jerger, Dept. of Mech. Eng. 
No. of

Copies

1

$\frac{\text { University of Oregon }}{\text { Eugene, Oregon }}$

J. L. Powe11, Physics Department

2

University of Tennessee

Knoxville, Tennessee

A. H. Nielsen, Physics Dept.

P. F. Pasqua, Nucl. Eng. Dept.

1

University of Toledo

J. J. Turin

2

University of Washington

Seattle, Washington

A. L. Babb, Dept. of Nucl. Eng.

K. L. Garlid

1

University of Wisconsin

Madison 6, Wisconsin

M. W. Carbon, Nuc1. Eng. Com .

3

USAEC Scientific Representative

c/o Atomic Energy of Canada Ltd.

Chalk River, Ontario, Canada

R. W. Ramsey

1

Virginia Polytechnic Institute

Blacksburg, Virginia

A. Robeson, Physics Department

1

Washington State University

Pullman, Washington

J. P. Spielman, Col. of Eng.

Westinghouse Electric Corporation (AEC)

C. A. Anderson

R. J. French

W. D. Leggett 


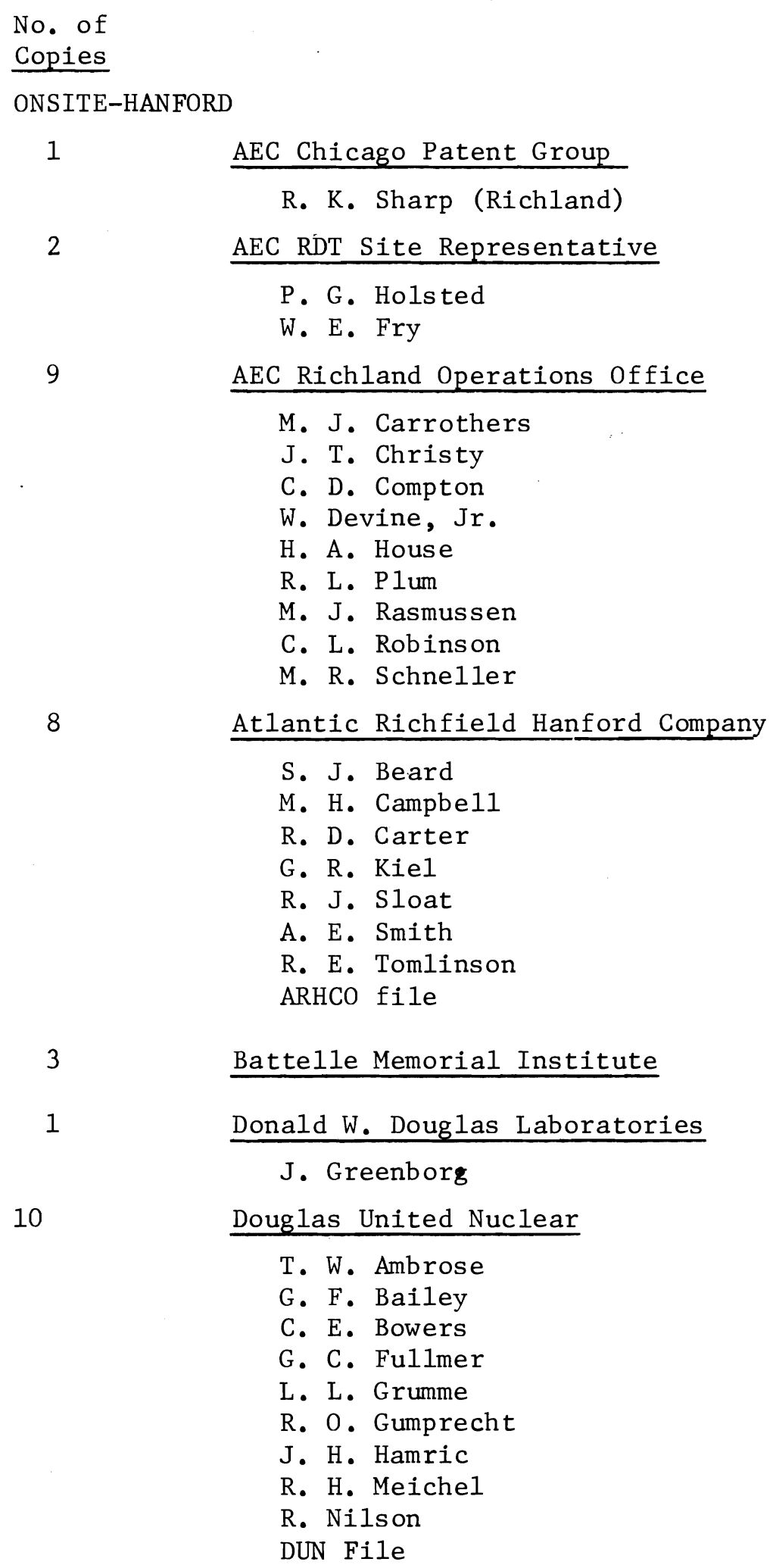


J. W. Kutcher

C. R. Lagergren

B. B. Lane

D. D. Lanning

G. A. Last

J. H. Lauby

B. R. Leonard, Jr.

W. R. Lewis

R. C. Liikala

C. W. Lindenmeier

R. C. Lloyd

R. P. Marshal1

R. P. Matsen

G. C. Moore

D. F. Newman

H. M. Parker

P. G. Parr

R. S. Paul

R. E. Peterson

W. W. Porath

D. L. Prezbindowski

C. R. Richey

L. C. Schmid (10)

R. I. Smith

W. P. Stinson

H. A. Taylor

C. R. Tipton, Jr.

V. O. Uotinen (10)

A. D. Vaughn

L. D. Williams

N. G. Wittenbrock

W. C. Wolkenhauer

J. R. Young

W. R. Young

Technical Publications (2)

Technical Information

Files (5)

H. L. Henry

P. L. Hofmann

U. P. Jenquin

R. L. Junkins

D. A. Kottwitz 